\title{
Characterization and intercomparison of aerosol absorption photometers: result of two intercomparison workshops
}

\author{
T. Müller ${ }^{1}$, J. S. Henzing ${ }^{2}$, G. de Leeuw ${ }^{2,3,6}$, A. Wiedensohler ${ }^{1}$, A. Alastuey ${ }^{7}$, H. Angelov ${ }^{8}$, M. Bizjak ${ }^{9}$,
} M. Collaud Coen ${ }^{10}$, J. E. Engström ${ }^{11}$, C. Gruening ${ }^{12}$, R. Hillamo ${ }^{4}$, A. Hoffer ${ }^{13}$, K. Imre ${ }^{13}$, P. Ivanow ${ }^{8}$, G. Jennings ${ }^{14}$, J. Y. Sun ${ }^{15}$, N. Kalivitis ${ }^{16}$, H. Karlsson ${ }^{17}$, M. Komppula ${ }^{5}$, P. Laj ${ }^{18,19}$, S.-M. Li ${ }^{20}$, C. Lunder $^{22}$, A. Marinoni ${ }^{23}$, S. Martins dos Santos ${ }^{12}$, M. Moerman ${ }^{2}$, A. Nowak ${ }^{1}$, J. A. Ogren ${ }^{24}$, A. Petzold ${ }^{25}$, J. M. Pichon ${ }^{18}$, S. Rodriquez ${ }^{26,27}$, S. Sharma ${ }^{21}$, P. J. Sheridan ${ }^{24}$, K. Teinilä ${ }^{4}$, T. Tuch ${ }^{1}$, M. Viana ${ }^{7}$, A. Virkkula ${ }^{6}$, E. Weingartner ${ }^{28}$, R. Wilhelm ${ }^{29}$, and Y. Q. Wang ${ }^{30}$

${ }^{1}$ Leibniz Institute for Tropospheric Research, Leipzig, Germany

${ }^{2}$ Netherlands Organisation for Applied Scientific Research, TNO, 80015 Utrecht, The Netherlands

${ }^{3}$ Finnish Meteorological Institute, Climate Change Unit, Helsinki, Finland

${ }^{4}$ Finnish Meteorological Institute, Air Quality Research, Helsinki, Finland

${ }^{5}$ Finnish Meteorological Institute, Kuopio Unit, Kuopio, Finland

${ }^{6}$ University of Helsinki, Dept of Physics, Helsinki, Finland

${ }^{7}$ Institute for Environmental Assessment and Water Research, Barcelona, Spain

${ }^{8}$ Institute for Nuclear Research and Nuclear Energy, Bulgarian Academy of Sciences, Sofia, Bulgaria

${ }^{9}$ University of Ljubljana, Faculty of Health Science, Ljubljana, Slovenia

${ }^{10}$ MeteoSwiss, Aerological Station, Les Invuardes, 1530 Payerne, Switzerland

${ }^{11}$ University of Stockholm, Department of Meteorology, Stockholm, Sweden

${ }^{12}$ European Commission - DG Joint Research Centre, IES/CCU, Ispra, Italy

${ }^{13}$ Department of Earth and Environmental Sciences, University of Pannonia, Pannonia, Hungary

${ }^{14}$ National University of Ireland, Galway, School of Physics/Environmental Change Institute, Galway, Ireland

${ }^{15}$ Key Laboratory for Atmospheric Chemistry, Center for Atmosphere Watch and Services, Chinese Academy of Meteorological Sciences, China Meteorological Administration, Beijing, 100081, China

${ }^{16}$ Nikos Kalivitis, Environmental Chemical Processes Laboratory, Dept. of Chemistry, Univ. of Crete, Heraklion, Greece

${ }^{17}$ Department of Applied Environmental Science, Stockholm University, Stockholm, Sweden

${ }^{18}$ CNRS/LaMP Université Blaise Pascal, 24, avenue des Landais, 63177 Aubière cedex, France

${ }^{19}$ Laboratoire de Glaciologie et Géophysique de l'Environnement Université Joseph Fourier, Grenoble 1/CNRS, 38400 St Martin d'Hères, France

${ }^{20}$ Air Quality Research Division, Science and Technology Branch, Environment Canada, 4905 Dufferin Street,

Toronto, Ontario, M3H 5T4, Canada

${ }^{21}$ Climate Research Division, Science and Technology Branch, Environment Canada, 4905 Dufferin Street,

Toronto, Ontario, M3H 5T4, Canada

${ }^{22}$ Norwegian Institute for Air Research, Kjeller, Norway

${ }^{23}$ Institute of Atmospheric Sciences and Climate, Via Gobetti 101, 40129 Bologna, Italy

${ }^{24}$ NOAA Earth System Research Laboratory, Boulder, CO 80305, USA

${ }^{25}$ Institute für Physik der Atmosphäre, DLR, Oberpfaffenhofen, Wessling, 82234, Germany

${ }^{26}$ Izaña Atmospheric Research Center, AEMET, Associated Unit to CSIC "Studies on Atmospheric Pollution", La Marina 20, planta 6, E38071, Santa Cruz de Tenerife, Canary Islands, Spain

${ }^{27}$ University of Huelva, Associated Unit to CSIC "Air Pollution”, Campus El Carmen, 21071, Huelva, Spain

${ }^{28}$ Laboratory of Atmospheric Chemistry, Paul Scherrer Institut, Villigen, Switzerland

${ }^{29}$ German Weather Service, Meteorological Observatory Hohenpeißenberg, Dept. GAW, 82383 Hohenpeißenberg, Germany

${ }^{30}$ Chinese Academy of Meteorological Sciences, Beijing, 100081, China

Received: 7 February 2010 - Published in Atmos. Meas. Tech. Discuss.: 7 April 2010

Revised: 23 November 2010 - Accepted: 1 December 2010 - Published: 10 February 2011

Published by Copernicus Publications on behalf of the European Geosciences Union. 
Abstract. Absorption photometers for real time application have been available since the 1980s, but the use of filterbased instruments to derive information on aerosol properties (absorption coefficient and black carbon, BC) is still a matter of debate. Several workshops have been conducted to investigate the performance of individual instruments over the intervening years. Two workshops with large sets of aerosol absorption photometers were conducted in 2005 and 2007. The data from these instruments were corrected using existing methods before further analysis. The intercomparison shows a large variation between the responses to absorbing aerosol particles for different types of instruments. The unit to unit variability between instruments can be up to $30 \%$ for Particle Soot Absorption Photometers (PSAPs) and Aethalometers. Multi Angle Absorption Photometers (MAAPs) showed a variability of less than 5\%. Reasons for the high variability were identified to be variations in sample flow and spot size. It was observed that different flow rates influence system performance with respect to response to absorption and instrumental noise. Measurements with non absorbing particles showed that the current corrections of a cross sensitivity to particle scattering are not sufficient. Remaining cross sensitivities were found to be a function of the total particle load on the filter. The large variation between the response to absorbing aerosol particles for different types of instruments indicates that current correction functions for absorption photometers are not adequate.

\section{Introduction}

Aerosols influence the radiation balance of the Earth through scattering and absorption of solar radiation. The importance of the direct effect of aerosols on climate has been pointed out by many authors (e.g. Charlson et al., 1991; Hansen et al., 1997; IPCC, 2001; Andreae, 2001). In order to study the role of aerosols on the radiation balance and reduce the uncertainties in the prediction of the direct effect of aerosols on climate change, field experiments have been conducted in the last decade, covering different aerosol characterization investigations at different locations (e.g. TARFOX, Russell et al., 1999; LACE 98, Ansmann et al., 2002; ACE-1, Bates et al., 1998; ACE-2, Raes et al., 2000; INDOEX, Ramanathan et al., 2001; SAMUM 1, Heintzenberg, 2009; EUCAARI, Kulmala et al., 2008). These studies reveal a large impact of aerosols on the transmission and reflection of solar radiation in the atmosphere, where scattering aerosols are responsible for the reflection of part of the solar irradiation back into space, and thus responsible for cooling because less radiation reaches the Earth surface. Absorbing aerosols may locally warm the atmosphere and influence meteorological processes

Correspondence to: T. Müller (muellert@tropos.de) and climate. The relative contributions of scattering and absorption are expressed through the single scattering albedo. There is a large uncertainty in the single scattering albedo and its global distribution. The latter can nowadays be estimated by using satellites (Veihelmann et al., 2007), but the technique is still at an early stage and relies on the determination of aerosol type from these satellite data. However, even when the aerosol type is known with some degree of confidence (Robles-Gonzalez et al., 2006), the absorption properties are poorly determined. Aerosol particles usually do not have a unique chemical composition: they may be either externally mixed as individual particles of a single composition or they may be internal mixtures of two or more major constituents with their own optical characteristics, which may not be representative of the mixture.

The use of dedicated instruments to determine the particle absorption coefficient from in situ measurements bears a large uncertainty. The aim of this paper is to determine the sources of these uncertainties through detailed analysis of systematic laboratory experiments using a representative sample of different types and makes of absorption photometers commonly deployed during field campaigns and many long-term monitoring sites. This broad suite of instruments allows for multiple instrument inter-comparisons and instrument characterizations. The characterization of scattering instrumentation has been presented elsewhere (Anderson et al., 1996; Heintzenberg et al., 2006; Müller et al., 2009).

Aerosol light absorption measurements typically show larger and more poorly understood uncertainties than extinction and scattering measurements. An important issue is the lack of a generally accepted reference or calibration standard. Network stations often rely on filter-based measurements where aerosols are collected on a fiber-filter matrix and the absorption is determined from the rate of change of light transmission through the particle loaded filter. However, it is well known that filter based techniques do not provide a true aerosol absorption coefficient and major corrections are needed. Several problems have been identified. Multiple scattering increases the optical path in the filter leading to enhanced absorption (Liousse et al., 1993; Bond et al., 1999; Weingartner et al., 2003). With increasing filter loading, the optical path in the particle loaded filter generally decreases, which effectively reduces the enhancement (LaRosa et al., 2002; Reid et al., 1998; Weingartner et al., 2003). Another problem concerns particle-related scattering effects (Liousse et al., 1993; Petzold et al., 1997; Bond et al., 1999; Weingartner et al., 2003; Lindberg et al., 1999; Petzold et al., 2005). Scattering of the incident light by particles increases the filter reflectance and hence reduces the transmission through the filter, which results in apparent absorption. Other problems include ill-defined spectral sensitivities for certain types of instruments, drift of flow, spot sizes that deviate from those provided by manufacturers, etc. Since all these factors affect the results of the measurement, they need to be well-characterized and corrected for. 
Dedicated instrument inter-comparisons and laboratory studies are needed to solve the problems described above and to better understand the measurements. Only a few studies have been performed and reported in the literature. In The First International Workshop on Light Absorption by Aerosol Particles, held at Colorado State University in 1980, many fundamentally different techniques measuring light absorption were compared (Gerber, 1982). After this rather comprehensive international workshop, instrument performance has been substantially improved and new instruments have been introduced. In 1999, a soot characterization experiment took place in the AIDA aerosol chamber in Karlsruhe, Germany (Saathoff et al., 2003). In that experiment, several different instruments for measuring carbon mass concentrations were compared using laboratory generated aerosols, e.g. diesel soot, spark generated "Palas" soot and internal mixtures of diesel soot and ammonium sulfate. The objective of the Reno Aerosol Optics Study (RAOS) conducted at the Desert Research Institute Reno in 2002, was to study the aerosol scattering, absorption and extinction under controlled conditions (Sheridan et al., 2005). The focus was to evaluate the accuracy of different measurement techniques. In 2007 the responses of four different instruments to fractal soot particles were inter-compared (Slowik et al., 2007). Another inter-comparison experiment with six different methods, including filter-based methods for measuring black carbon and elemental carbon is given in Park et al. (2006). All the above studies have the common feature that instruments from different manufacturers and/or using different techniques were compared. However, they do not provide statistics on the performance of multiple instruments of the same make and type.

In this article, results are presented from two absorption photometer workshops which were conducted in 2005 and 2007 at IfT (Leibniz Institute for Tropospheric Research) Leipzig, Germany. The first of these workshops was held in the framework of WMO Global Atmosphere Watch (GAW) and in collaboration with the EU FP6 Network of Excellence ACCENT (Atmospheric Composition Change: A European Network) in 2005. This workshop is denoted as GAW2005 throughout this paper. The second workshop was part of an EU FP6 Integrated Infrastructures Initiatives (I3) project EUSAAR (European Supersites for Atmospheric Aerosol Research), in collaboration with GAW and ACCENT. This workshop is denoted as EUSAAR2007. The goals of the workshops and the frameworks in which they were organized are presented in Sect. 2. In Sect. 3, the approach and experimental set up is described. The workshops focused on filterbased light absorption methods since these are widely used in the global aerosol monitoring networks, despite all the necessary known and poorly understood corrections. An advantage of filter based instruments is that the detection limit is lower compared to other techniques, e.g. photoacoustic or extinction minus scattering. The detection limit is important for ambient air monitoring especially at low concentrations.
A benefit of workshops such as these would be a better understanding of the filter-based instruments, with the goal of eventually being able to relate the filter-based absorption measurements to one of the more robust reference methods. The selected instruments MAAP, PSAP, and Aethalometer are introduced in Sect. 4. A rather complete instrument characterization is presented in Sect. 5. We present the unit-tounit variability between instruments of the same make and type, after applying commonly used correction algorithms in Sect. 6. A summary of the results and the conclusions and recommendations are presented in Sect. 7.

\section{Goals and objectives}

The objective of EUSAAR is the integration of measurements of atmospheric aerosol properties performed in a distributed network of 20 European ground-based stations. The measurements include physical and optical properties of carbonaceous aerosols. The overall objective of the EUSAAR activity on optical properties is to integrate and harmonize measurements of aerosol optical properties at the EUSAAR sites, with the outcome of having a sustainable and reliable observation network for aerosol optical data across Europe with known and high quality that are readily accessible in a common format. This requires the development of standard procedures for routine measurements of optical parameters (aerosol scattering coefficient, aerosol absorption coefficient and aerosol optical depth). Because different types of instruments are used for this purpose, it is difficult to assess the quality of the data and compare results from the various stations. Therefore, specific objectives and standard operating procedures were developed to ensure that data from the network stations are harmonized:

1. Develop a protocol providing aerosol optical measurements to ensure that they all adhere to a schedule of regular calibration and quality assurance for the relevant instruments and make data available on-line in a common format.

2. Develop calibration procedures for the various instruments at the EUSAAR sites for measurement of aerosol optical properties of aerosol scattering and absorption coefficient and of aerosol optical depth.

3. Develop quality assurance (QA) procedures to determine uncertainties for the instrumentation and data on aerosol optical properties at the EUSAAR sites.

4. Harmonize aerosol optical property data bases which are accessible via a single webpage.

The objectives of the GAW and EUSAAR workshops discussed in this paper address specific objectives 2 and 3, for absorption measurements, in support of the EUSAAR, GAW, and ACCENT activities on (a) Training and education, 
(b) Development of QA procedures, and (c) Establishing the scientific basis to provide data of high quality with known uncertainty.

The specific goals of the workshops were:

i. To characterize instruments.

ii. To determine the variability amongst several photometers of the same type/manufacturer.

iii. To compare absorption photometers of different types.

iv. To determine the response of absorption photometers to well-characterized generated aerosol.

v. To train users of filter-based absorption photometers on the use and maintenance of these instruments to obtain the optimum results.

\section{Approach and experimental set up}

\subsection{Tasks}

The tasks to be achieved for these objectives were:

i. Instrument characterization.

a. Determination of the effective wavelength for which the absorption coefficient is valid.

Emitted spectral radiation of light sources in absorption photometers was measured. For broad emission spectra, the spectral sensitivity of the detector was included.

b. Determination of filter spot sizes.

Bond et al. (1999) observed variation in sample spot size for PSAPs and included measured spot sizes in their correction method. Actual spot sizes that differ from the spot size that is included in the instrument software, directly translates to erroneous absorption coefficients. Spot sizes (or rather spot areas) of PSAPs, MAAPs and Aethalometers were measured.

\section{c. Aerosol flow characterization.}

Incorrect flow directly translates to an erroneous absorption coefficient. As pointed out by Anderson et al. (1999), the effect of spot-area and flow correction is potentially larger than the instrument unit-to-unit variability. Another flow characterization concerns the face velocity, i.e. the ratio of volume flow and spot area. Face velocities were increased and lowered to estimate upper and lower bounds for optimal operation.

ii. Determination of the variability of the results amongst several photometers of the same type/manufacturer, following correction by widely used absorption photometer correction functions. iii. Comparison of absorption photometers of different types to determine differences between instruments as a consequence of their characteristics, measurement principles and corrections.

iv. Determination of the response of absorption photometers to well-characterized, laboratory generated aerosol and ambient aerosol.

Inter-comparison experiments for strongly absorbing (carbon black) and moderately absorbing (ambient air) aerosols were done. Sensitivity to purely scattering aerosol was investigated with ammonium sulfate $-\left(\mathrm{NH}_{4}\right)_{2} \mathrm{SO}_{4}$, which does not absorb light at wavelengths in the visible part of the electromagnetic spectrum.

Experimental runs with ambient air were done in order to compare the response to a "real" atmospheric aerosol. Ambient aerosol particles may consist of an unknown mass fraction of organics and may be coated with absorbing or nonabsorbing liquids. Artifacts due to evaporation and/or condensation may be possible. Experiments which deal with these effects have been done in recent years (e.g. Subramanian et al., 2007; Lack et al., 2008; and Cappa et al., 2008). In Lack et al. (2008) and Cappa et al. (2008) it was found that PSAP overestimates absorption significantly in the presence of organic matter. Although it is important to understand biases in filter based measurements due to organics and liquids, dedicated experiments concerning the response to organics were not performed during the workshops. To achieve tasks (i) to (iv) it was chosen to use well defined aerosols and not to generate aerosols with large amount of organics or liquids.

\subsection{Experimental set-up}

Solutions of ammonium sulfate and carbon black (Printex 75, Evonik Degussa $\mathrm{GmbH}$ ) were atomized for aerosols with defined composition. The aerosol was dried by diffusion dryers and fed into a $0.5 \mathrm{~m}^{3}$ stainless steel mixing chamber as shown in Fig. 1. Absorption photometers were connected to six of the eight output ports of the mixing chamber. Two output ports were used for additional aerosol characterization using a Scanning Mobility Particle Sizer (SMPS) and an aerodynamic particle sizer (APS, TSI model 3321) to measure number size distributions, and an integrating nephelometer (TSI, model 3563) to measure scattering coefficients.

Before the GAW2005 workshop the mixing chamber was tested for possible differences of aerosol concentration at the outlet ports. Particle number concentrations at the outlet ports were measured with two Condensation Particle Counters (CPC), which were checked for measuring the same concentration before testing the chamber. Eight tests with different combinations of ports were done. The aerosol source was dried ambient air with a total aerosol flow of about $15 \mathrm{lpm}$ through the chamber. It was found that differences in aerosol 


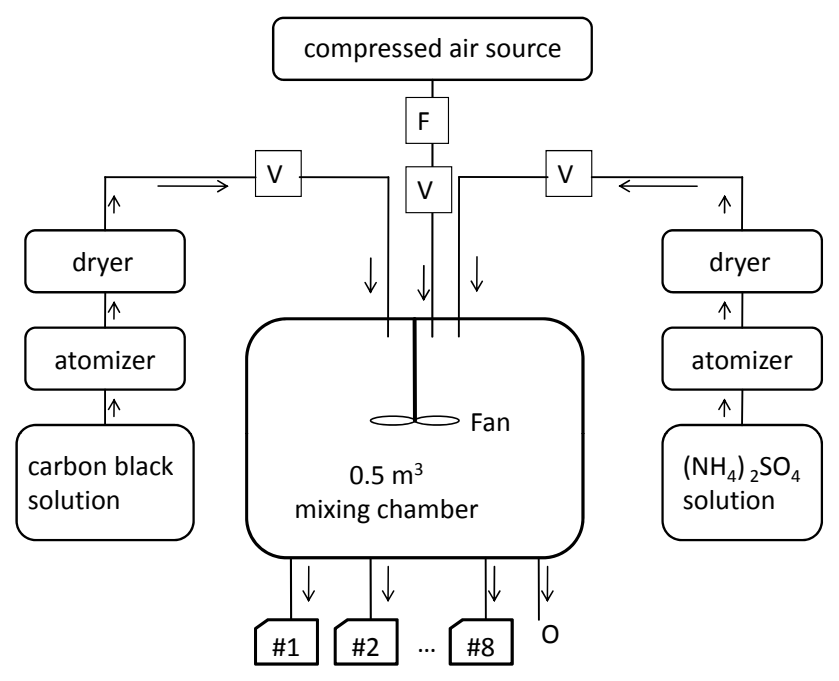

Fig. 1. Experimental setup for runs with ammonium sulfate and soot. Concentrations of ammonium sulfate and carbon black aerosols were adjustable. The aerosol was dried before entering the chamber. Direction of aerosol flow is indicated by arrows. In this diagram, $\mathrm{F}=$ filter, $\mathrm{V}=$ valve, $\mathrm{O}=$ overflow. Instruments were connected to output ports 1 to 8 .

concentration were smaller than $1.5 \%$ for all eight ports. Afterwards filtered air with the same flow rate was fed into the chamber. The aerosol concentration was reduced by half after about $10 \mathrm{~min}$. After three hours no particles were measured. This test showed that it is possible to use one chamber for different types of aerosols after flushing the chamber with particle free air.

Measurements of ambient air were done in a different way. With the mixing chamber it would be impossible to compare all instruments at the same time because of the limited number of aerosol outlets of the chamber. Thus for ambient air measurements the instruments were placed with their aerosol inlets at the same distance to the windows of the laboratory and the windows were opened. The laboratory air conditioning was switched off during these experiments. The relative humidity was measured in the inlet of a nephelometer and was always lower than $35 \%$, even during overnight runs.

\subsection{Aerosol characterization}

\subsubsection{Particle scattering coefficient}

Scattering and backscattering coefficients were measured using an integrating nephelometer at wavelengths of 450, 550, and $700 \mathrm{~nm}$. This nephelometer measures the integrated intensity of light scattered at angles between $7^{\circ}$ and $170^{\circ}$. This limitation and an imperfect light source result in underestimation of the scattering coefficient. Corrections for this so called "truncation error" were discussed in Literature. Anderson and Ogren (1998) presented a correction for the TSI 3565 nephelometer based on the wavelength dependence of the scattering coefficient, which is derived from the nephelometer itself. This correction was obtained for less absorbing aerosols with real parts of refractive index between 1.40 and 1.52 and for imaginary parts below 0.01 . In Massoli et al. (2009) it was shown, that the uncertainty using the correction by Anderson and Ogren (1998) can be up to $30 \%$ for absorbing particles with refractive index of $1.7-0.3 i$, what is mostly due to the high real part of refractive index. In Bond et al. (2009) it was suggested, that the correction should be calculated using Mie theory to minimize errors. We followed this approach and corrected the scattering coefficients using Mie theory (e.g. Anderson et al., 1996). For ambient or black particles the uncertainties in the truncation correction of nephelometer data do not significantly influence the filter based absorption measurements, since light passing the filter is dominated by particle absorption.

\subsubsection{Particle number size distribution}

The particle number size distributions were measured using a SMPS in the size range from $10 \mathrm{~nm}$ to $600 \mathrm{~nm}$ of electrical mobility diameter. Larger particles, in the aerodynamic size range from 0.5 to $20 \mu \mathrm{m}$, were measured with an APS. The aerodynamic diameter $d_{\text {aer }}$ is related to the equivalent geometrical particle diameter $d_{\mathrm{p}}$ by

$d_{\mathrm{p}}=d_{\mathrm{aer}} \cdot \sqrt{\chi_{\mathrm{p}} / \rho_{\mathrm{p}}}$,

where $\rho_{\mathrm{p}}$ is the particle density and $\chi_{\mathrm{p}}$ is the dynamic shape factor of the particle. For ambient aerosol and ammonium sulfate we used a particle density of $1.7 \mathrm{~g} \mathrm{~cm}^{-3}$ and a dynamic shape factor of unity. Using a dynamic shape factor of unity, the electrical mobility diameter equals the geometrical diameter. For carbon black, the same values were used, since the particle number concentration measured in the size range of the APS were too low and do not contribute significantly to the volume concentration or optical properties.

\subsection{Aerosol characterization results}

The particle number size distributions of ambient aerosol, ammonium sulfate, and carbon black used in the GAW2005 workshop are shown in Fig. 2 and those for the EUSAAR2007 workshop are shown in Fig. 3. Physical and optical characteristics are given in Tables 1 and 2 . The effective radius, defined by

$R_{\mathrm{eff}}=\frac{\int r^{3} n(r) d r}{\int r^{2} n(r) d r}$

is the area weighted mean radius of the particle number size distribution. The single scattering albedo

$\omega_{0}=\frac{\sigma_{\mathrm{sp}}}{\sigma_{\mathrm{sp}}+\sigma_{\mathrm{ap}}}$

is calculated for the actual wavelengths of the Radiance Research $3 \lambda$-PSAP as measured during the RAOS experiment 
Table 1. Average values of properties of aerosol types used during GAW2005; maximum and minimum values are given between parentheses. Absorption coefficients were measured by PSAP and MAAP and scattering coefficients were determined by a nephelometer.

\begin{tabular}{lrrr}
\hline aerosol type & ambient air & ammonium sulfate $^{1}$ & carbon black \\
\hline Effective radius, $R_{\text {eff }}[\mu \mathrm{m}]$ & 0.141 & 0.056 & 0.087 \\
Single scattering albedo & 0.92 & 1.0 & 0.46 \\
$\omega_{0}$ at $637 \mathrm{~nm}$ & $(0.90,0.94)$ & (by definition) & $(0.45,0.47)$ \\
$\omega_{0}$ at $530 \mathrm{~nm}$ & 0.90 & 1.0 & 0.35 \\
& $(0.89,0.91)$ & (by definition) & $(0.33,0.50)$ \\
Scattering coefficients, & 97.37 & 95.6 & 56.7 \\
$\sigma_{\text {sp }}$ at $550 \mathrm{~nm}[1 / \mathrm{Mm}]$ & $(67.4,126.6)$ & $(89.7,100.6)$ & $(18.7,90.3)$ \\
Absorption coefficients, & 11.8 & 0.0 & 119.8 \\
$\sigma_{\text {ap }}$ at $637 \mathrm{~nm}[1 / \mathrm{Mm}]$ & $(8.3,15.4)$ & $($ by definition $)$ & $(76.6,137.4)$ \\
Ångström scattering exponents & 1.39 & 2.57 & 1.02 \\
$\alpha_{\text {sp }}(450$ and $700 \mathrm{~nm})$ & $(1.25,1.50)$ & $(2.51,2.64)$ & $(0.96,1.30)$ \\
Ångström absorption exponents & 1.14 & not & 0.80 \\
$\alpha_{\text {ap }}(460$ and $700 \mathrm{~nm})$ & $(1.09,1.24)$ & defined & $(0.73,0.86)$ \\
\hline
\end{tabular}

1 The single scattering albedo of ammonium sulfate is set to unity. It is assumed that the absorption coefficient is zero.

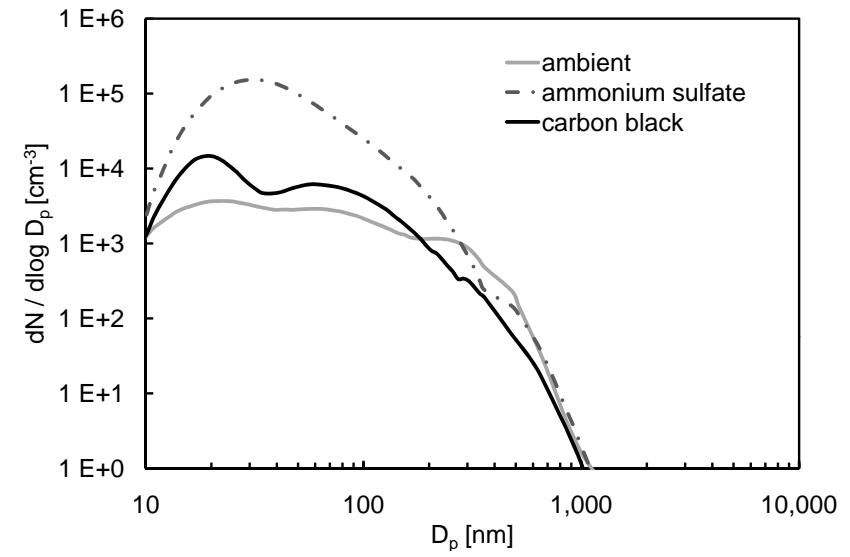

Fig. 2. Particle number size distributions for ambient air, ammonium sulfate, and carbon black during GAW2005. The particle number size distribution is a composite of number size distributions measured with a SMPS and an APS.

in 2002 (Sheridan et al., 2005). Absorption coefficients measured by PSAP were corrected using the Bond correction scheme (Bond et al., 1999), which is described in Sect. 4. Scattering and absorption coefficients were measured at different wavelengths. Methods for a wavelength adjustment of scattering and absorption coefficients are given in Sect. 4.

\section{Absorption photometers description}

Several types of instruments for measuring aerosol light absorption coefficients are commercially available.

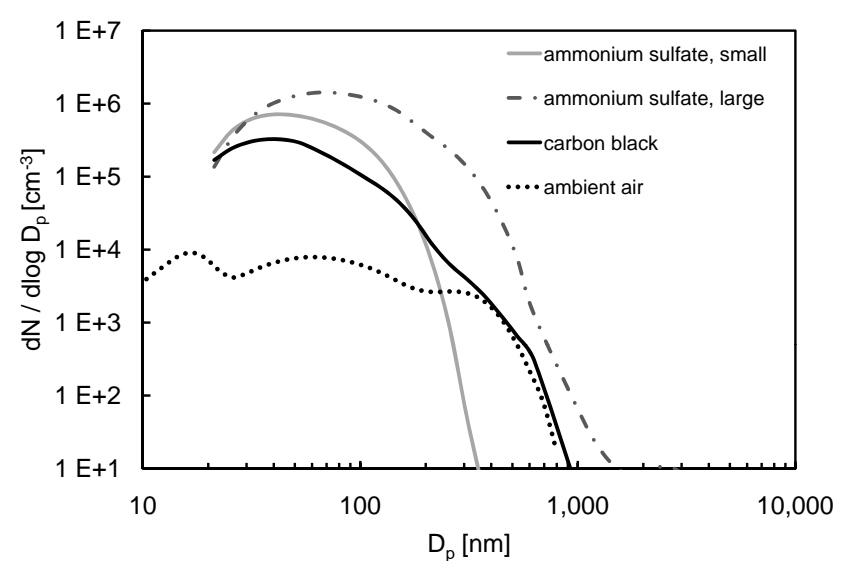

Fig. 3. Particle number size distributions for two sizes for ammonium sulfate, for carbon black, and for ambient air during EUSAAR2007. The number distributions for ammonium sulfate and carbon black are composites of number distributions measured with the SMPS and the APS. For ambient air APS measurements were not available.

Filter-based instruments measure the change of transmittance through a fiber filter as particles are deposited. The complex relationship between change in light transmission and aerosol absorption and scattering on the filter requires a calibration of these filter-based methods.

The Aethalometer (Magee Scientific, Berkeley, USA; Hansen et al., 1984) is offered in different configurations. The model AE31 measures light transmittance through the filter at seven wavelengths, from 370 to $950 \mathrm{~nm}$. The ability to measure multispectral absorption coefficients provides 
Table 2. Average values of properties of aerosol types used during EUSAAR2007; maximum and minimum values are given between parentheses. For Ammonium sulfate minimum and maximum values are omitted, since single scattering albedo and Ångström exponent were very stable during experiments. The optical properties of ammonium sulfate are the same as those given in Table 1 for GAW2005, only the effective radius is different.

\begin{tabular}{lrr}
\hline aerosol type & $\begin{array}{r}\text { ambient air, } \\
\text { two experiments }\end{array}$ & $\begin{array}{r}\text { ammonium sulfate, } \\
\text { two experiments }\end{array}$ \\
\hline$R_{\text {eff }}[\mu \mathrm{m}]$ & 0.15 & 0.045 \\
& & 0.097 \\
$\omega_{0}$ at $637 \mathrm{~nm}$ & $0.75(0.67,0.81)$ & 1.0 \\
& $0.86(0.76,0.91)$ & \\
$\omega_{0}$ at $530 \mathrm{~nm}$ & $0.78(0.72,0.83)$ & \\
& $0.87(0.80,0.91)$ & \\
Scattering coefficients, & $60.8(38.6,75.7)$ & $1045(980,1116)$ \\
$\sigma_{\text {sp }}$ at $550 \mathrm{~nm}[1 / \mathrm{Mm}]$ & $107.2(64.4,216.4)$ & $570(309,1272)$ \\
Absorption coefficients, & $17.66(9.88,29.2)$ & not measured \\
$\sigma_{\text {ap }}$ at $637 \mathrm{~nm}[1 / \mathrm{Mm}]$ & $12.0(6.39,21.26)$ & 3.2 \\
$\alpha_{\text {sp }}(450$ and $700 \mathrm{~nm})$ & 1.91 & 0.61 \\
& 1.6 & not defined \\
$\alpha_{\text {ap }}(460$ and $650 \mathrm{~nm})$ & $1.08(1.01,1.20)$ & \\
& $0.99(0.76,1.20)$ &
\end{tabular}

insight in the chemical composition of the absorbing material. Corrections for this instrument type were developed by several investigators (Weingartner et al., 2003; Arnott et al., 2005; Schmid et al., 2006; Collaud Coen et al., 2009). Another correction of the loading effect was shown by Virkkula et al. (2007), in which the reported BC concentration is not converted to absorption coefficients.

The Particle Soot Absorption Photometer (PSAP, Radiance Research, Seattle, USA), originally measured light absorption at one wavelength in the green, and correction schemes for this instrument were developed by Bond et al. (1999) and Virkkula et al. (2005). A three wavelength model was developed later, with wavelengths of $467 \mathrm{~nm}$, $530 \mathrm{~nm}$ and $660 \mathrm{~nm}$ (Virkkula et al., 2005). Corrections applied to data of the PSAP and the Aethalometer require the particle scattering coefficient, often measured with nephelometers.

An inherent correction method for minimizing the cross sensitivity to particle scattering was realized for another instrument type, the Multi Angle Absorption Photometer (MAAP, Thermo Fisher Scientific, Waltham, USA). In addition to the filter light transmittance, the MAAP measures the reflectivity of the filter at two angles. A radiative transfer model implemented in the MAAP relates the measured signals to the particle absorption coefficient (Petzold et al., 2004). The MAAP and the Aethalometer utilize a filter tape drive mechanism providing automatic filter advance, which facilitates long term monitoring of aerosol absorption.
Instruments for aerosol characterization were similar for both workshops and are given in Table 3. The instruments tested during the workshops GAW2005 and EUSAAR2007 are presented in Tables 4 and 5, respectively. In order to compare reported values, measured absorption and scattering coefficients were corrected to standard temperature and pressure conditions (STP, $0^{\circ} \mathrm{C}$ and $1013.25 \mathrm{hPa}$ ). A more detailed description of the instruments and correction methods is given in the following sections.

\subsection{PSAP}

The operating principle of the PSAP is described in Bond et al. (1999). The PSAP with a nominal wavelength of $565 \mathrm{~nm}$ is referred to as the old PSAP. In the new PSAP the light source was replaced by a diode emitting light at a shorter wavelength of about $530 \mathrm{~nm}$. In addition, the opal glass plate between light source and particle filter was replaced by a diffusely scattering hemisphere. A prototype, 3-wavelength PSAP was developed as described by Virkkula et al. (2005) with optical wavelengths of 467, 530, and $660 \mathrm{~nm}$. This instrument differed slightly from the commercial version developed later, particularly with regard to the optical diffuser. The wavelengths of PSAPs available at the workshops were checked using an optical spectrometer. Methods and results are presented in Sect. 5.

PSAP correction schemes were developed by Bond et al. (1999) (in the following referred to as Bond correction) and Virkkula et al. (2005). For the PSAP inter-comparison, most notably the unit-to-unit variability, the Bond correction was applied to all types of PSAP, although it was developed for the old PSAP type instruments. The Bond correction accounts for flows and spot sizes that differ from the values used for internal calculations and for loading and scattering artefacts. The correction was developed for the old PSAP having a nominal wavelength of $565 \mathrm{~nm}$, whereas the applied scattering correction uses scattering coefficients at $550 \mathrm{~nm}$, the center wavelength of the green channel of a TSI-nephelometer (TSI, model 3563). The scattering coefficients used for the Bond correction are not corrected for the so called truncation error (Anderson, 1996; Heintzenberg, 2006; Müller et al., 2009). Correction of the $3 \lambda$-PSAP requires the corresponding scattering coefficients. The interpolation and extrapolation of scattering coefficients was done using the scattering Ångström exponent $\alpha_{\mathrm{sp}}$ which is defined by:

$\alpha_{\mathrm{sp}}\left(\lambda_{1}, \lambda_{2}\right)=\frac{-\ln \left(\sigma_{\mathrm{sp}}\left(\lambda_{2}\right) / \sigma_{\mathrm{sp}}\left(\lambda_{1}\right)\right)}{\ln \left(\lambda_{2} / \lambda_{1}\right)}$

With scattering coefficients measured at three wavelengths, an average scattering Ångström exponent has been calculated. A similar equation can be used to determine the absorption Ångström exponent $\alpha_{\mathrm{ap}}$, which allows to adjust absorption coefficients to other wavelengths. The overall 
Table 3. Instrumentation used for aerosol characterization during the GAW2005 and EUSAAR2007 workshops.

\begin{tabular}{|c|c|c|}
\hline Type & measured property & Manufacturer \\
\hline Nephelometer & particle scattering- and back- scattering coefficient & TSI \\
\hline Model, 3565 & at wavelengths 450,550 , and $700 \mathrm{~nm}$ & \\
\hline TDMPS $^{1}$ & $\begin{array}{l}\text { particle number size distribution from } 10 \text { to } 650 \mathrm{~nm} \\
\text { electrical mobility }\end{array}$ & custom made \\
\hline SMPS $^{2}$ & $\begin{array}{l}\text { particle number size distribution from } 20 \text { to } 650 \mathrm{~nm} \\
\text { electrical mobility }\end{array}$ & custom made \\
\hline $\begin{array}{l}\text { APS, } \\
\text { model } 3321\end{array}$ & $\begin{array}{l}\text { Particle number size distribution from } 580 \mathrm{~nm} \text { to } \\
10 \mu \mathrm{m} \text { aerodynamic diameter }\end{array}$ & TSI \\
\hline
\end{tabular}

${ }^{1}$ GAW2005; ${ }^{2}$ EUSAAR2007

Table 4. Absorption photometers at the GAW2005 workshop.

\begin{tabular}{|c|c|c|c|c|}
\hline Type & $\begin{array}{l}\text { Nominal } \\
\text { wavelength(s) } \\
{[\mathrm{nm}]}\end{array}$ & $\begin{array}{l}\text { Actual } \\
\text { wavelength(s) } \\
{[\mathrm{nm}]}\end{array}$ & Manufacturer & $\begin{array}{l}\text { Serial } \\
\text { Numbers/ } \\
\text { Identification }\end{array}$ \\
\hline PSAP & $565^{1}$ & 585 & Rad. Res. $^{2}$ & $48,20 \mathrm{~A}, 20 \mathrm{~B}, 13$ \\
\hline PSAP & $565^{1}$ & 522 & Rad. Res. $^{2}$ & 71 \\
\hline $3 \lambda$-PSAP & $470,530,660^{5}$ & $467,531,650$ & Rad. Res. $^{2}$ & $90 \mathrm{~A}, 90 \mathrm{~B}$ \\
\hline PSAP & 532 & & custom made & MISU, ITM \\
\hline MAAP & $670^{1}$ & 637 & Thermo $^{3}$ & $\begin{array}{l}1 \mathrm{~A}, 13,30,32, \\
49,50\end{array}$ \\
\hline $\begin{array}{l}\text { Aethalometer } \\
\text { model AE31 }\end{array}$ & $\begin{array}{l}370,470,520,590 \\
660,880,950\end{array}$ & & $\begin{array}{l}\text { Magee } \\
\text { Scientific }^{4}\end{array}$ & $483,563,337$ \\
\hline $\begin{array}{l}\text { Aethalometer } \\
\text { model AE21 }\end{array}$ & 370,880 & & $\begin{array}{l}\text { Magee } \\
\text { Scientific }^{4}\end{array}$ & 426 \\
\hline $\begin{array}{l}\text { Aethalometer } \\
\text { model AE9 }\end{array}$ & white light & & $\begin{array}{l}\text { Magee } \\
\text { Scientific }^{4}\end{array}$ & 910101 \\
\hline $\begin{array}{l}\text { Aethalometer } \\
\text { model AE10 }\end{array}$ & white light & & $\begin{array}{l}\text { Magee } \\
\text { Scientific }^{4}\end{array}$ & 70010 \\
\hline
\end{tabular}

\footnotetext{
${ }^{1}$ Nominal wavelength given by manufacturer differs significantly from wavelength measured during workshop.

2 Radiance Research, Seattle, WA

3 Thermo Fisher Scientific, Waltham, USA

${ }^{4}$ Magee Scientific Company, Berkeley, CA, USA

${ }^{5}$ Sheridan et al. (2005)
}

correction, which is based on the procedure described in Bond et al. (1999), is given by

$$
\begin{aligned}
\sigma_{\mathrm{ap}}(t)= & \frac{A}{Q \cdot \Delta t} \ln \left(\frac{I(t-\Delta t)}{I(t)}\right) \\
& \cdot \frac{1}{1.317 \cdot \tau+0.866}-0.016 \cdot \sigma_{\mathrm{sp}}
\end{aligned}
$$

with sample spot area $A$, volumetric flow rate $Q$, time interval between readings $\Delta t$, optical transmission relative to a blank filter $\tau$, and the measured intensity $I(t)$. As mentioned before, this correction originally was derived for the wavelength $565 \mathrm{~nm}$. In Ogren (2010) a modification of this correction is shown, which allows to apply the Bond correction for other wavelenths.

The approach presented in Virkkula et al. (2005) and Virkkula (2010) was not used. A comparison of different correction schemes would complicate a discussion of the workshop results. It was estimated that the PSAP correction by Virkkula gives about $6 \%$ higher values compared to 
Table 5. Aerosol absorption photometers at the EUSAAR2007 workshop.

\begin{tabular}{|c|c|c|c|}
\hline Type & $\begin{array}{l}\text { Nominal } \\
\text { wavelength(s) }[\mathrm{nm}]\end{array}$ & Manufacturer & $\begin{array}{l}\text { Serial } \\
\text { Numbers }\end{array}$ \\
\hline PSAP & 565 & Rad. Res. & 15 (leak), 20, 28, 60, 80 \\
\hline PSAP & $467,530,660$ & Rad. Res. & $103,106,100,483$ \\
\hline PSAP & 531 & Custom made & MISU \\
\hline PSAP & 523 & Custom made & Lund, ITML, NILU \\
\hline MAAP & $670^{*}$ & Thermo & $\begin{array}{l}13,24,34,56,59 \\
80,81\end{array}$ \\
\hline $\begin{array}{l}\text { Aethalometer } \\
\text { model AE31 }\end{array}$ & $\begin{array}{l}370,470,520,590 \\
660,880,950\end{array}$ & Magee Scientific & $217,427,351,408$ \\
\hline $\begin{array}{l}\text { Aethalometer } \\
\text { model AE16 }\end{array}$ & 880 & Magee Scientific & 199,531 \\
\hline
\end{tabular}

* Nominal wavelength given by manufacturer differs significantly from wavelength measured during workshop.

the Bond correction for single scattering albedos between 0.8 and 0.9. The Bond correction was apllied to all PSAP data throughout the paper.

\subsection{MAAP}

The MAAP measures the radiation transmitted through and scattered back from a particle-loaded filter. A two-stream radiative transfer model is used to minimize the cross sensitivity to particle scattering. A detailed description of this method can be found in Petzold et al. (2004). Although MAAP measures absorption coefficients, the values reported by the instrument are given as mass concentration of black carbon (BC).

The MAAP operation manual gives the operating wavelength as $670 \mathrm{~nm}$. During the Reno Aerosol Optics Study (RAOS), MAAP absorption was compared (Petzold et al., 2005) to a reference absorption measurement (Sheridan et al., 2005). The reference absorption coefficient was calculated both as the difference between measured extinction and scattering coefficients and from photoacoustic photometry. Absorption coefficients measured by the reference technique were adjusted to $670 \mathrm{~nm}$ using the Ångström law with an Ångström exponent of 1.02. From regression analysis of the MAAP and the reference absorption, a regression line with a slope of $0.99 \pm 0.01$ was calculated for pure black carbon particles.

However, during the GAW2005 workshop, it was found that the optical wavelength of MAAP is $637 \pm 1 \mathrm{~nm}$ instead of $670 \mathrm{~nm}$. The full width at half maximum (FWHM) of the emitted light is about $18 \mathrm{~nm}$. The consequences of this wavelength mismatch are:

a. The MAAP can be used for aerosol particles with an absorption Ångström exponent close to unity to give directly the absorption at $670 \mathrm{~nm}$. b. As described above, the MAAP compares excellently with the photoacoustic reference adjusted to $670 \mathrm{~nm}$, whereas the real MAAP wavelength is $637 \mathrm{~nm}$. For an Ångström exponent of 1.02, the absorption coefficient at $637 \mathrm{~nm}$ should be $5 \%$ higher than at $670 \mathrm{~nm}$. Hence, for this Ångström exponent, the measured absorption coefficient at $637 \mathrm{~nm}$ is $5 \%$ low and should therefore be corrected by multiplication with a factor of 1.05 .

Throughout the entire paper, the following correction was applied to MAAP data:

$\sigma_{\mathrm{ap}}^{637 \mathrm{~nm}}=m_{\mathrm{BC}} \cdot Q_{\mathrm{BC}} \cdot 1.05$,

where $m_{\mathrm{BC}}$ is the equivalent mass concentration of black carbon reported by the instrument and $Q_{\mathrm{BC}}=6.6 \mathrm{~m}^{2} / \mathrm{g}$ is the specific absorption coefficient of black carbon used in the firmware of MAAP.

\subsection{Aethalometer}

Several versions of Aethalometers were used in both workshops. In this section we briefly describe the operating principle of Aethalometers. A more complete description can be found in the user manual (Hansen, 2005).

The Aethalometer measures the attenuation $\operatorname{ATN}(\lambda, t) \mathrm{de}-$ fined by

$\operatorname{ATN}(\lambda, t)=-\ln \left(I(\lambda, t=0)_{0} / I(\lambda, t)\right)$,

where $I_{0}$ is the intensity of light that passes through a pristine portion of the filter and $I$ is the intensity of light that passes through the particle-laden filter. The change in light attenuation by filter loading during a time interval $\Delta t$ defines the attenuation coefficient $\sigma_{\mathrm{ATN}}$ as

$\sigma_{\mathrm{ATN}}=\frac{\operatorname{ATN}(\lambda, t+\Delta t)-\operatorname{ATN}(\lambda, t)}{\Delta t} \cdot \frac{A}{F}$, 
where $A$ is the area of the filter spot and $F$ is the volumetric flow rate. The aethalometer internal software converts the measured attenuation coefficient into equivalent black carbon mass concentration $\left(m_{\mathrm{BC}}\right)$ using

$m_{\mathrm{BC}}=\frac{\sigma_{\mathrm{ATN}}}{\mathrm{SG}_{\mathrm{BC}}}$,

where $\mathrm{SG}_{\mathrm{BC}}=14625 / \lambda\left[\mathrm{m}^{2} / \mathrm{g}\right.$ ] (wavelength given in $\mathrm{nm}$ ) is the spectral mass specific attenuation cross-section. The Aethalometer reports $m_{\mathrm{BC}}$ rather than the attenuation coefficient $\sigma_{\mathrm{ATN}}$.

The attenuation coefficients $\sigma_{\mathrm{ATN}}$ were converted to absorption coefficients $\sigma_{\text {ap }}$ using the correction given in Weingartner et al. (2003) with

$\sigma_{\mathrm{ap}}=\sigma_{\mathrm{ATN}} /(C \cdot R(\mathrm{ATN}))$,

where the factor $C=2.14$ is introduced for the correction of multiple light-scattering effects of the filter fibers. More recently, Collaud Coen et al. (2009) evaluated a newly developed and four already existing, aethalometer correction schemes and concluded that this value for $C$ is too low and should be at least 2.9. Average $C$ values for several datasets varied between 2.9 and 4.3. However, Collaud Coen et al. (2009) recommend further analysis to extend their results to obtain a more universal multiple scattering correction factor. Awaiting the results from such research, we used the original value of $C=2.14$ throughout this paper.

The factor $R$ accounts for the reduction of the optical path length in the filter with increasing filter load:

$$
\begin{aligned}
& R(\mathrm{ATN})=(1 / f-1) \\
& \quad \cdot[\ln (\mathrm{ATN})-\ln (10 \%)] /[\ln (50 \%)-\ln (10 \%)]+1,
\end{aligned}
$$

where $f=a\left(1-\omega_{0}\right)+1$ with $a=0.87$. This correction is referred to as the Weingartner correction in the rest of the paper.

All Aethalometers are corrected by the same experiment/measurement-period average $f$ value. A difficulty using this correction is to derive the $f$ value, since it depends on single scattering albedo $\omega_{0}$ and thus on the absorption coefficient. To avoid a circular reference, the single scattering albedo was determined using the absorption coefficient measured with MAAP and scattering coefficient measured with nephelometer. To adjust the measured scattering and absorption to other wavelengths, the Ångström exponents for scattering and absorption were used. Ångström exponents for absorption were derived from corrected PSAP values. The Weingartner correction was applied to all Aethalometer data throughout the paper.

\section{Absorption photometer characterization}

\subsection{Emission wavelengths of absorption photometers}

The spectral emitted radiation of absorption photometers was measured with a grating spectrophotometer (HR2000, Ocean
Optics Inc.) equipped with a fiber optic connector. One end of an optical fiber was connected to the spectrophotometer and the other end was held into the measurement head of the photometer and measured the directly emitted light of the diodes. A wavelength dependency of the filter transmittance is negligible, since the spectral width of the emitted light is small compared to the spectral transmittance of the filter (see Arnott, et al., 2005). Examples of measured spectra are shown in Fig. 4. The measured intensity spectra $I(\lambda)$ were corrected for the spectral sensitivity of the spectrometer detector $S_{\mathrm{S}}(\lambda)$ and the grating efficiency $\chi_{\mathrm{S}}(\lambda)$. The spectral sensitivity of the photometer detector $S_{\mathrm{P}}(\lambda)$ was also taken into account. Values for $S_{\mathrm{P}}(\lambda)$ were taken from datasheets of typically used silicon detectors. The effective wavelength is defined as the first moment of the sensitivity corrected spectra

$\lambda_{\mathrm{eff}}=\frac{\int \lambda \cdot I_{\mathrm{corr}}(\lambda) d \lambda}{\int I_{\mathrm{corr}}(\lambda) d \lambda}$,

with the sensitivity-corrected intensity

$I_{\text {corr }}(\lambda)=\frac{S_{\mathrm{P}}(\lambda)}{S_{\mathrm{S}}(\lambda) \cdot \chi_{\mathrm{S}}(\lambda)} \cdot I(\lambda)$.

Results from these measurements are summarized in Table 6 and are discussed below.

\subsubsection{PSAP}

Several types of PSAPs (Radiance Research) were tested during both workshops. Instruments with serial numbers 13,15 , 20A, 20B, 28, 48, and 60 had a peak of the light emission at wavelength $565 \mathrm{~nm}$. A tail of the emitted radiation at longer wavelengths causes an effective wavelength of about $585 \mathrm{~nm}$. For a typical wavelength dependence of $\lambda^{-1}$ the ratio of absorption coefficients at 565 and $585 \mathrm{~nm}$ is 1.035 . A newer instrument with serial number 71 had a symmetrical intensity distribution with FWHM of $20 \mathrm{~nm}$ and a peak wavelength of $522 \mathrm{~nm}$. The three-wavelength PSAPs show peak wavelengths at 467 (FWHM $20 \mathrm{~nm}), 531$ (FWHM $40 \mathrm{~nm}$ ), and $650 \mathrm{~nm}$ (FWHM $22 \mathrm{~nm}$ ), slightly different than the detector weighted averaged wavelengths of 467,530 and $660 \mathrm{~nm}$ given for the prototype instrument in Virkkula et al. (2005). The measured spectral radiances (without sensitivity correction) are shown in Fig. 4a. The three intensity spectra of $3 \lambda$-PSAPs could not be measured separately because the instrument switches between the different light sources at a frequency which is faster than the integration time of the spectrophotometer.

\subsubsection{Aethalometer}

Spectra of the seven-wavelength and two-wavelength Aethalometer models are shown in Fig. $4 b$ and c. Only spectra of one specific instrument of each type are shown. No significant differences between instruments of the same 

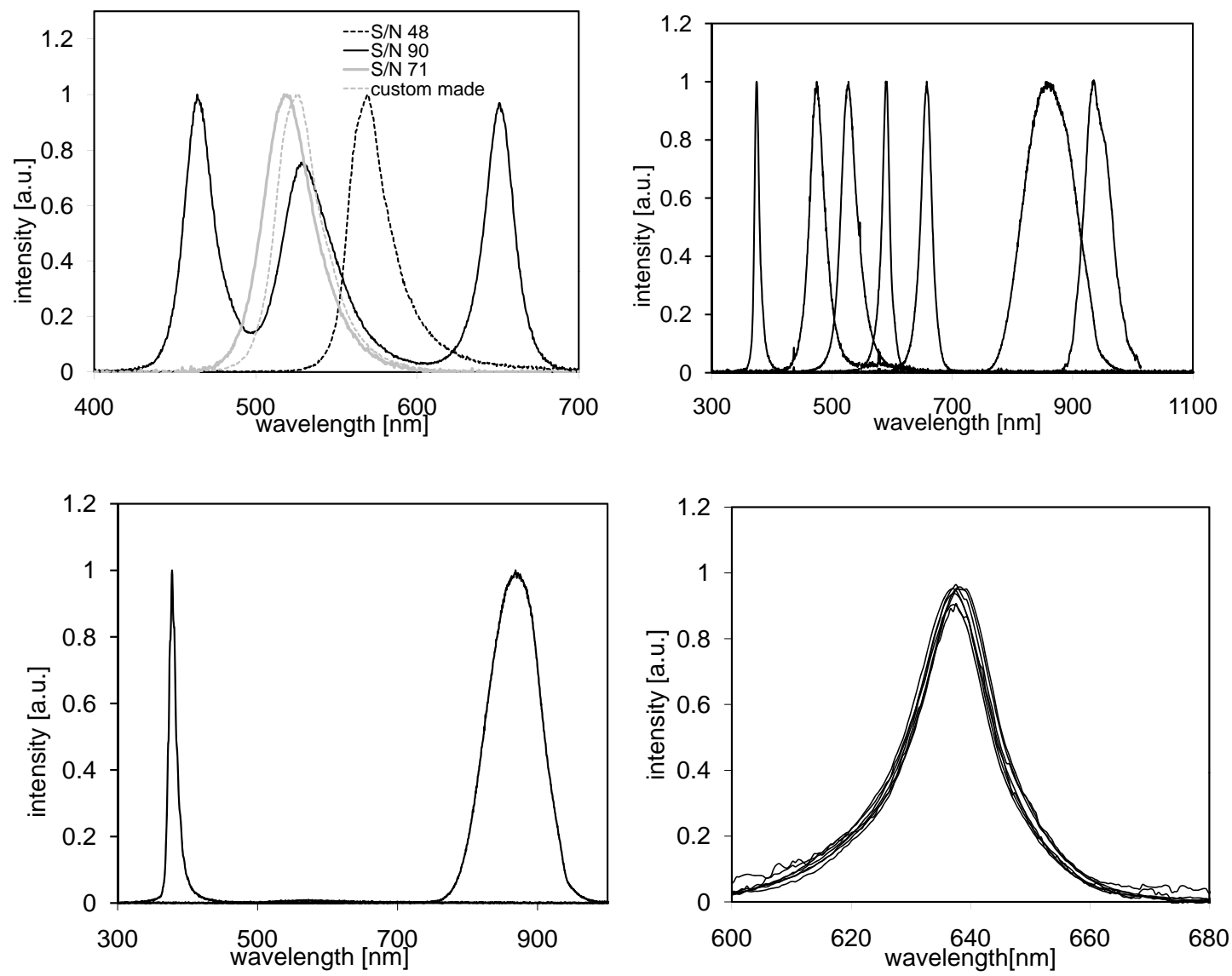

Fig. 4. Normalized spectral emission of light sources of absorption photometers. (a) different types of PSAPs; single wavelength Radiance Research PSAPs ( $S / N$ 48, S/N 71); three wavelength Radiance Research PSAP ( $/ N$ 90); custom made (ITM). (b) seven wavelength Aethalometer model AE31 ( $S / N$ 563). (c) two wavelength Aethalometer model AE21 ( $/ N$ 426) and (d) seven MAAPs.

Table 6. Nominal and measured wavelengths of optical absorption photometers.

\begin{tabular}{lllll}
\hline $\begin{array}{l}\text { Photometer } \\
\text { type }\end{array}$ & $\begin{array}{l}\text { Nominal } \\
\text { wavelengths } \\
{[\mathrm{nm}]}\end{array}$ & $\begin{array}{l}\text { Measured } \\
\text { wavelengths } \\
{[\mathrm{nm}]}\end{array}$ & $\begin{array}{l}\text { Full width } \\
\text { at half } \\
\text { maximum [nm] }\end{array}$ & $\begin{array}{l}\text { Number of } \\
\text { instruments }\end{array}$ \\
\hline PSAP & 565 & $585 \pm 6$ & 35 & 4 \\
$3 \lambda$-PSAP & $467,530,660$ & $467,531,650$ & $20,40,22$ & 1 \\
$\begin{array}{l}\text { Custom made } \\
\text { PSAP }\end{array}$ & $532 \pm 2$ & 40 & 1 \\
MAAP & 670 & $637 \pm 1$ & $18+1$ & 7 \\
Aethalometer model & 370 & $376 \pm 2$ & $11 \pm 1$, & 3 \\
AE31 & 470 & $473 \pm 2$ & $30 \pm 2$, & \\
& 520 & $525 \pm 7$ & $34 \pm 2$, & \\
& 590 & $593 \pm 4$ & $17 \pm 3$, & \\
& 660 & $654 \pm 4$ & $23 \pm 2$, & \\
& 880 & $858 \pm 5$ & $85 \pm 6$, & \\
Aethalometer model & 950 & $940 \pm 1$ & $50 \pm 10$ & 15,80 \\
AE21 & 370,880 & 378,867 & & \\
\hline
\end{tabular}


type were observed. Spectra of white light Aethalometers are not shown. Reasons are the unknown spectral sensitivity of the detector of the Aethalometer and the upper limit of the wavelength range of the Ocean Optics spectrophotometer. Estimates of the emitted spectral radiation and the effective wavelength of this Aethalometer are reported by Weingartner et al. (2003), who specifies the effective wavelength to be $855 \mathrm{~nm}$ for unloaded filters. Weingartner et al. (2003) also noted that the effective wavelength depends on the particle loading, which causes a wavelength dependent attenuation of the transmitted light $(I(\lambda)$ in Eq. 13). This fact makes it much more difficult to accurately estimate the effective wavelength for white light Aethalometers.

\subsubsection{MAAP}

Emission wavelengths of MAAPs are shown in Fig. 4d. There is not significant difference between seven MAAPs. It is important to note, that the emission wavelenght is $637 \mathrm{~nm}$ and not $670 \mathrm{~nm}$, as given in the user manual.

\subsection{Measurement of spot areas}

Spot areas of absorption photometers are going directly into the calculation of absorption coefficients. For instance, the spot area is used in the Bond correction of PSAP to account for the difference from a reference spot area. During both workshops spot areas produced on the filter were measured with optical reticles for PSAP and the MAAP and with vernier calipers for the Aethalometer.

\subsubsection{PSAP}

Spot areas of six (GAW2005) and eleven (EUSAAR2007) filters were measured by different workshop participants. Average and standard deviation are given in Table 7. On average, spot areas are about 6\% smaller (EUSAAR2007) and $1 \%$ larger (GAW2005) than the reference spot area of $20.43 \mathrm{~mm}^{2}$ used in the Bond correction. The uncertainty (standard deviation) of the measured spot size for one individual filter by different people was on average $4 \%$. Figure 5 shows a plot of the standard deviation versus the spot area for different PSAPs. It can be seen, that the standard deviation increases with increasing spot area. It is not clear if this behavious is caused by good or bad sealings rings.

\subsubsection{Aethalometer}

Aethalometers can be purchased with two different spot sizes, i.e. the "High Sensitivity" (HS) spot size measuring $0.5 \mathrm{~cm}^{2}$ and the "Extended Range" (ER) spot area of $1.67 \mathrm{~cm}^{2}$. The choice of spot area may depend on the level of pollution at a monitoring site and the sensitivity that is needed. The greatest sensitivity is achieved with a small spot area and the highest air flow. The disadvantage of greater sensitivity is that transmission goes down in a shorter period

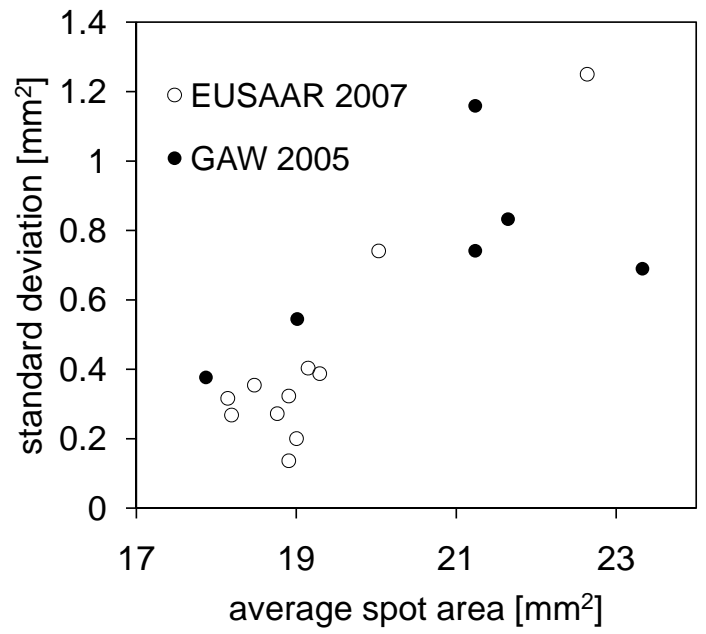

Fig. 5. Standard deviation of PSAP spot area versus average spot area. Each point is for one PSAP. The nominal spot area given by the manufacturer is $17.85 \mathrm{~mm}^{2}$.

of time, which leads to more interruptions of data due to filter transport. During the GAW2005 workshop the spots of three HS and one ER and during the EUSAAR2007 workshop the spots of three HS and two ER types of instruments were measured.

To test the objectivity of spot area measurements, the spot areas for all instruments available during EUSAAR2007 were measured three times, by two persons. The standard deviation of the distribution of the measurements for a single spot $\left(0.02 \mathrm{~cm}^{2}\right)$ is similar to the standard deviation of the average spot sizes collected from various instruments $\left(0.03 \mathrm{~cm}^{2}\right)$ provided in Table 8 , which shows the average spot areas for all Aethalometers for both workshops. The average spot areas for the high sensitivity spots are $4 \%$ larger (EUSAAR2007) and 8\% lower (GAW2005) than those reported by the manufacturer. Likewise, for the extended range spots, the areas were 2\% larger (EUSAAR2007) and 4\% smaller (GAW2005) than those specified by the manufacturer. There is no explanation for differences among both workshops. Measuring the spot size with a caliper might be subjective, but there is no evidence that this is the only reason for differences among both workshops. Changes of the design of Aethalometer between the workshops are excluded to be responsible for differences. We conclude that for Aethalometers the spot sizes differ by less than $8 \%$ from the spot sizes reported by the manufacturer. Data of Aethalometers from both workshops were not corrected for spot size variations.

\subsubsection{MAAP}

Spot sizes of all available MAAP instruments did not show a significant variation within the accuracy of the measurement $(0.1 \mathrm{~mm}$ in diameter). Consequently, it is not expected that 
Table 7. Measured PSAP spot areas. The ratio of measured spot areas to the reference spot area of $20.43 \mathrm{~mm}^{2}$ is given in parentheses.

\begin{tabular}{lcc}
\hline & EUSAAR2007 & GAW2005 \\
\hline number of PSAPs & 11 & 6 \\
measurements for each PSAP & 8 & 6 \\
average area $\left[\mathrm{mm}^{2}\right]$ & $19.23(0.94)$ & $20.72(1.01)$ \\
standard deviation $\left[\mathrm{mm}^{2}\right]$ & 1.25 & 1.96 \\
\hline
\end{tabular}

variability in spot sizes has an effect on the determination of absorption coefficients with MAAP.

\subsection{Test with various flow rates}

During EUSAAR2007 the response the absorption photometer to different flow rates was investigated by varying instrument pumps flows. Prior to these experiments the pressure and temperature sensors and flow rates were calibrated.

\subsubsection{MAAP}

For MAAPs, the standard flow rate was $16.71 \mathrm{pm}$ (liters per minute). Prior to the sensitivity test, the unit-to-unit variability of seven MAAPs was determined. The unit-to-unit variability is defined by the coefficient of variation (CV), which is the ratio of the standard deviation and the average absorption coefficient measured simultaneously with a set of instruments. For MAAP the unit to unit variability was $\mathrm{CV}=3 \%$. Before the sensor calibrations, $\mathrm{CV}$ was $11 \%$; hence a proper flow calibration is a key to proper functioning of the instruments.

The set of instruments was split into two groups. One group of three instruments ("standard set") was continuously operated at the standard flow of $16.7 \mathrm{lpm}$. The second group, consisting of four instruments ("test set"), was operated at different flows of $16.7 \mathrm{lpm}, 10 \mathrm{lpm}$ and $6 \mathrm{lpm}$. At $16.7 \mathrm{lpm}$, the unit-to-unit variabilities of the standard and test sets were $2 \%$ and $3 \%$, respectively. The absorption coefficient obtained with the test set was on average $1.9 \%$ higher than for the standard set. This value is within the uncertainty of the unit-to-unit variability of $3 \%$, and shows that there is no bias caused by selecting instruments for the test set. At a flow rate of $10 \mathrm{lpm}$ the average absorption coefficient of the test set was $1.7 \%$ lower than the test set. The unit-to-unit variabilities of the standard and the test sets were $1 \%$ and $4 \%$, respectively. At a flow rate of $61 \mathrm{pm}$ the unit-to-unit variability of the test set increased to $13 \%$, and the average absorption coefficient was $5 \%$ smaller than that of the standard set.

The flow of $6 \mathrm{lpm}$ is smaller than the recommended minimum flow of $8.3 \mathrm{lpm}$ and it is not clear if the flow regulation works properly at that flow. Problems with the flow regulation outside of the specifications could cause the higher unit
Table 8. Measured Aethalometer spot areas. HS and ER refer to models with "high sensitivity" and "extended range" spots with nominal spot area $0.5 \mathrm{~cm}^{2}$ and $1.67 \mathrm{~cm}^{2}$, respectively. The ratio of measured and reference spot area is given between parentheses.

\begin{tabular}{llcc}
\hline & & EUSAAR2007 & GAW2005 \\
\hline \multirow{4}{*}{ HS } & number of instruments & 3 & 3 \\
& measurements for each instrument & 3 & 3 \\
& average area $\left[\mathrm{cm}^{2}\right]$ & $0.52(1.04)$ & $0.46(0.92)$ \\
& standard deviation $\left[\mathrm{cm}^{2}\right]$ & 0.03 & 0.06 \\
\hline \multirow{4}{*}{ ER } & number of instruments & 2 & 1 \\
& measurements for each instrument & 3 & 1 \\
& average area $\left[\mathrm{cm}^{2}\right]$ & $1.71(1.02)$ & $1.60(0.96)$ \\
& standard deviation $\left[\mathrm{cm}^{2}\right]$ & 0.03 & - \\
\hline
\end{tabular}

to unit variability and the difference of $5 \%$ in the average absorption coefficient. The results from these experiments confirm that the minimum flow rate should be $8.3 \mathrm{lpm}$ as recommended in the instrument manual. Differences in the absorption coefficient with flows between 16.7 and $10 \mathrm{lpm}$ are not significant.

\subsubsection{Aethalometer}

The Aethalometer flow rate recommended by the manufacturer is $2-61 \mathrm{pm}$. For the "High Sensitivity" (HS, $0.5 \mathrm{~cm}^{2}$ ) and "Extended Range" (ER, $1.67 \mathrm{~cm}^{2}$ ) spot sizes, the recommended flow rates correspond to different face velocities, what is the ratio of flow rate and spot area size. For HS and ER, 2-61pm corresponds to face velocities of 67-200 and $20-60 \mathrm{~cm} / \mathrm{s}$, respectively.

Due to the limited number of instruments, the larger unitto-unit variability and different spot sizes the suite of instruments could not be divided into two sets. Therefore a facefactor ff was introduced by

$\mathrm{ff}=\frac{\left.\left[\sigma_{\text {ap }}^{\text {test }} \text { (test flow) } / \sigma_{\text {ap }}^{\text {avg }}(4 \mathrm{lpm})\right]\right|_{\text {test period }}}{\left.\left[\sigma_{\text {ap }}^{\text {test }}(4 \mathrm{lpm}) / \sigma_{\mathrm{ap}}^{\mathrm{avg}}(4 \mathrm{lpm})\right]\right|_{\text {reference period }}}$

where $\sigma_{\text {ap }}^{\text {test }}$ is the absorption coefficient measured with a single test instruments at a standard flow of $4 \mathrm{lpm}$ or at different test flows. $\sigma_{\mathrm{ap}}^{\mathrm{avg}}$ is the average absorption coefficient of five remaining Aethalometers operated with standard flow. Ratios of $\sigma_{\text {ap }}^{\text {test }}$ and $\sigma_{\text {ap }}^{\text {avg }}$ were measured for tests periods with varying flows and the reference period.

Two Aethalometers with ER spot were chosen as test instruments and were operated at flows (face velocity) of $1.91 \mathrm{pm}(0.19 \mathrm{~m} / \mathrm{s}), 4.0 \mathrm{lpm}(0.4 \mathrm{~m} / \mathrm{s}), 5.9 \mathrm{lpm}(0.59 \mathrm{~m} / \mathrm{s})$, and $6.8 \mathrm{lpm}(0.68 \mathrm{~m} / \mathrm{s})$. The experiments with flows of $4.0 \mathrm{lpm}$ were used as reference. The average face-factors determined for the two ER Aethalometers at flows of 1.9, 5.9, and $6.8 \mathrm{lpm}$ were $1.01,1.06$, and 0.90 , respectively. One 
Aethalometer with HS spot was operated with a flow of $6.5 \mathrm{lpm}(2.2 \mathrm{~m} / \mathrm{s})$. The face factor for this experiment was $\mathrm{ff}=1.16$

These flow experiments indicate that Aethalometers should not be operated with flows at the high end of the recommended range. At that flow rate, significant changes, overestimations as well as underestimations in absorption coefficients that are larger than the instrumental noise and unitto-unit variability were observed.

\subsubsection{PSAP}

A flow test for PSAP was conducted during the GAW2005 workshop. Data were corrected according the Bond correction, and wavelengths were adjusted to $532 \mathrm{~nm}$ using the Ångström exponent measured by three wavelength PSAPs. A reference set of two PSAPs was operated with a flow of $1.1 \mathrm{lpm}$ and a test set of four PSAPs was operated with a flow of $2.2 \mathrm{lpm}$. Absorption coefficients of the test set were higher by $20 \%$ compared to the reference set. For another experiment the flow of the test set was lowered to $0.5 \mathrm{lpm}$ and absorption coefficients of the test set were higher by $12 \%$. For both, higher and lower flow rates the test set showed higher absorption values than the reference set at a flow of $1.1 \mathrm{lpm}$. Differences between test set and reference set were about 5\% when operating both sets a $1 \mathrm{lpm}$. There are differences up to $20 \%$ when operating PSAPs at different flow rates.

\subsubsection{Summary of tests with various flow rates}

For MAAP significant differences due to changes of the flow rate were not observed. For Aethalometer and PSAP deviations up to $20 \%$ were measured. A clear conclusion, which is the best flow rate for each instrument type can not be given. We suggest that all absorption photometers should be operated within the range of recommended flow rates by the manufactures.

Influences on the sensitivity are not only expected by the flow rate, but also by the particle sizes. Both, changes of the flow rate and the particle size can alter the particle penetration depth into the filter. Nakayama et al. (2010) showed in a study that flow rates of 0.3 and $0.7 \mathrm{lpm}$ can cause differences of about $12 \%$ for PSAP. In the same study it was shown that different particle sizes can change the sensitivity of up to $100 \%$. Moteki et al. (2010) presented a model to simulate particle deposition and the impact on the radiative transfer, which qualitatively reflects results from Nakayama et al. (2010). A final decision on the best flow rates requires both, model calculations and experiments with ambient aerosols.

\subsection{Instrumental noise}

The instrumental noise was determined by the analysis of filtered, particle-free air (relative humidity $<30 \%$ ) measurements. Absorption coefficients of different types of photometers were corrected using the standard correction schemes (Bond and Weingartner). Averaging times were one minute for PSAP, three minutes for Aethalometer, and one (EUSAAR2007) or five (GAW2005) minutes for MAAP. The instrumental noise is defined as the single standard deviation of absorption coefficients and can be interpreted as the uncertainty of a single readout. The noise was determined for each individual instrument. Average, maximum and minimum noise of instruments of the same type is given in Table 9 .

\subsubsection{PSAP}

Instrumental noise for the PSAP was determined at a flow rate of $1 \mathrm{lpm}$. The noise determined during GAW2005 was about $0.06 \mathrm{Mm}^{-1}$ for all three wavelengths of a $3 \lambda$-PSAP. For $1 \lambda$-PSAPs the average noise was $0.36 \mathrm{Mm}^{-1}$. The difference in noise for both instrument types cannot be explained, since it is not known which changes have been made to the light source, the detector, and the electronics in the $3 \lambda$-PSAPs. During EUSAAR2007, the average noise of six $3 \lambda$-PSAPs $\left(0.07 \mathrm{Mm}^{-1}\right)$ was similar to the GAW2005 results and the average noise of two $1 \lambda$-PSAPs $\left(0.15 \mathrm{Mm}^{-1}\right)$ was lower compared to GAW2005.

The noise characteristics of the PSAP and the dependence on the integration time $(\Delta t)$ were investigated by Springston and Sedlacek (2007). It is assumed that the time between two consecutive measurements is equal to the integration time. From analysis of the error propagation they showed that the PSAP signal noise should be proportional to $\Delta t^{-1.5}$. As pointed out by Springston and Sedlacek (2007) this result is not quite the same as recording the data and then averaging the data during post processing. This latter technique yields a noise reduction proportional to the square root of the averaging time. Theoretically this dependence should be valid for all types of filter based absorption photometers. In contrast, experiments done by Sedlac et al. (2007) showed that the noise of the PSAP varies with $\Delta t^{-1.3}$ and the noise was determined to be $1.6 \mathrm{Mm}^{-1}$ for an averaging time of $2 \mathrm{~s}$. Using this noise time relationship the noise of PSAP should be $0.02 \mathrm{Mm}^{-1}$ for an averaging time of $60 \mathrm{~s}$. However, the lowest values for instrumental noise at averaging time of $60 \mathrm{~s}$ found during the GAW2005 and EUSAAR2007 workshops are about $0.05 \mathrm{Mm}^{-1}$ and thus 2.5 times higher than the value derived from Springston and Sedlacek (2007).

\subsubsection{MAAP}

The noise of the MAAP at a flow rate of $10 \mathrm{lpm}$ was determined to be $0.08 \mathrm{Mm}^{-1}$ during GAW2005 for five minutes averaging time and $0.22 \mathrm{Mm}^{-1}$ for EUSAAR2007 for one minute averaging time. In the user manual of MAAP, the detection limit for two minutes averaging time (95\% confidence level) is given as $0.66 \mathrm{Mm}^{-1}$, which corresponds to a noise 
Table 9. Instrumental noise measured during the workshops for different photometer types.

\begin{tabular}{|c|c|c|c|c|c|c|}
\hline \multirow[t]{2}{*}{ Photometer } & \multirow[t]{2}{*}{ Workshop } & \multirow{2}{*}{$\begin{array}{l}\text { Averaging } \\
\text { time [min] }\end{array}$} & \multirow{2}{*}{$\begin{array}{l}\text { number of } \\
\text { instruments }\end{array}$} & \multicolumn{3}{|c|}{ Noise $[1 / \mathrm{Mm}]$} \\
\hline & & & & average & Min & Max. \\
\hline MAAP & GAW2005 & 5 & 6 & 0.08 & 0.06 & 0.13 \\
\hline $3 \lambda$-PSAP blue & GAW2005 & 1 & 1 & 0.06 & & \\
\hline $3 \lambda$-PSAP green & GAW2005 & 1 & 1 & 0.05 & & \\
\hline $3 \lambda$-PSAP red & GAW2005 & 1 & 1 & 0.05 & & \\
\hline $1 \lambda$-PSAP green & GAW2005 & 1 & 3 & 0.36 & 0.30 & 0.46 \\
\hline $\begin{array}{l}7 \lambda \text { Aethalometer } \\
(370 \mathrm{~nm})\end{array}$ & GAW2005 & 3 & 1 & 0.42 & & \\
\hline $\begin{array}{l}7 \lambda \text { Aethalometer } \\
(880 \mathrm{~nm})\end{array}$ & GAW2005 & 3 & 1 & 0.17 & & \\
\hline $\begin{array}{l}\text { AE10 white light } \\
\text { Aethalometer }\end{array}$ & GAW2005 & 3 & 1 & 1.84 & & \\
\hline MAAP & EUSAAR2007 & 1 & 7 & 0.22 & 0.22 & 0.23 \\
\hline $3 \lambda$-PSAP blue & EUSAAR2007 & 1 & 6 & 0.07 & 0.04 & 0.16 \\
\hline $3 \lambda$-PSAP green & EUSAAR2007 & 1 & 6 & 0.07 & 0.04 & 0.15 \\
\hline $3 \lambda$-PSAP red & EUSAAR2007 & 1 & 6 & 0.06 & 0.04 & 0.14 \\
\hline $1 \lambda$-PSAP green & EUSAAR2007 & 1 & 2 & 0.15 & 0.14 & 0.16 \\
\hline $\begin{array}{l}7 \lambda \text { Aethalometer } \\
(\lambda=470-880 \mathrm{~nm}) \text { ER spot }\end{array}$ & EUSAAR2007 & 3 & 2 & 0.80 & 0.60 & 1.01 \\
\hline $\begin{array}{l}7 \lambda \text { Aethalometer } \\
(\lambda=470-880 \mathrm{~nm}) \mathrm{HS} \text { spot* }\end{array}$ & EUSAAR2007 & 3 & 2 & 0.38 & 0.36 & 0.40 \\
\hline $\begin{array}{l}1 \lambda \text {-Aethalometer } \\
(880 \mathrm{~nm})\end{array}$ & EUSAAR2007 & 3 & 2 & 0.28 & 0.21 & 0.35 \\
\hline
\end{tabular}

* For comparability Aethalometer noise is converted to 3-min averages (see Sect. 5.4 for explanatory text).

level (single standard deviation) of about $0.33 \mathrm{Mm}^{-1}$. Following the $\Delta t^{-1.5}$ relation the measured noise for two minutes averaging time would be $0.31 \mathrm{Mm}^{-1}$ and $0.08 \mathrm{Mm}^{-1}$ for GAW2005 and EUSAAR2007, respectively.

\subsubsection{Aethalometer}

During GAW2005 the averaging time for $7 \lambda$ - Aethalometers (AE31) was three minutes, whereas the minimum averaging time of a white light Aethalometer (AE10) was 2 min. The flow rate of Aethalometers was $4 \mathrm{lpm}$. The instrumental noise levels discussed below are representative for the wavelength range 470 to $880 \mathrm{~nm}$. For convenience of comparison, we apply the theoretical $\Delta t^{-1.5}$ noise dependence (Springston and Sedlacek, 2007) to relate the obtained 2min noise values to noise values that would have been obtained if the instrument "averaging period" was $3 \mathrm{~min}$. During GAW2005 the 3 min noise level of AE31 photometers was $0.42 \mathrm{Mm}^{-1}$ at a wavelength of $370 \mathrm{~nm}$ and $0.17 \mathrm{Mm}^{-1}$ at a wavelength of $880 \mathrm{~nm}$. The noise level of the white light Aethalometer (AE10) adjusted to three minutes averaging time was much higher with a value of $1.84 \mathrm{Mm}^{-1}$.

During EUSAAR2007, noise levels were determined for measurements at a 2 min averaging time for the $7 \lambda$ Aethalometers and a $1 \mathrm{~min}$ instrument-averaging time for the single wavelength aethalometers. The standard deviations of filtered air measurements of Aethalometers with ER spots $\left(1.5 \mathrm{Mm}^{-1}\right)$ were markedly higher than the standard deviations for instruments with HS spots $\left(0.7 \mathrm{Mm}^{-1}\right)$. After conversion to a $3 \mathrm{~min}$ averaging time using the $\Delta t^{-1.5}$ noise dependence the noise reduces to $0.80 \mathrm{Mm}^{-1}$ and $0.38 \mathrm{Mm}^{-1}$ for the ER- and HS-Aethalometers, respectively. For the single wavelength Aethalometers, the 3 min averaging noise value was $0.28 \mathrm{Mm}^{-1}$.

\section{Instrument intercomparison}

\subsection{Reference instrument}

The MAAP was used as "reference instrument" for absorption measurements (cf. Sect. 4.2). The MAAP certainly suffers as all filter based methods to a cross sensitivity to scattering. Therefore MAAP can not be a "true" absorption reference instrument, as e.g. extinction minus scattering measurements or photoacoustic spectrometer. The choice to use MAAP as reference instrument is based on the results from the RAOS study (Sheridan et al., 2005), with good agreement between photoacoustic spectrometer measurements and absorption obtained from the difference between extinction (from an extinction cell) and scattering (from a nephelometer). Another reason is, that the unit to unit variability of 
less than $5 \%$ is low compared to other instrument. During the GAW2005 and EUSAAR2007 workshops, other instruments had been expected to provide extinction-scattering or photoacoustic data to obtain the reference absorption, but all instruments failed for one reason or another. Therefore MAAP was the only alternative.

\subsection{Ambient air}

To account for the wavelength dependence of the aerosol absorption, PSAP and Aethalometer absorption coefficients were adjusted to the MAAP wavelength of $637 \mathrm{~nm}$. The wavelength adjustment uses the respective absorption Ångström exponent measured with $3 \lambda$-PSAP and $7 \lambda$ Aethalometer. Ångström exponents are fits through absorption coefficeints of all three wavelengths for PSAPs. For PSAPs, the Ångström exponent for absorption was 1.14 during GAW2005 and 1.08 and 0.99 for two different experiments during EUSAAR2007. For Aethalometers, the applied Ångström exponent for absorption obtained from channels 520, 590, 660, and $880 \mathrm{~nm}$, was 0.97 for GAW2005 and 1.06 for EUSAAR2007, respectively. Prior to wavelength adjustment, absorption coefficients measured with PSAPs and Aethalometers were corrected using the Bond and Weingartner corrections, respectively. The relative sensitivity $\varepsilon^{n}$ of an individual instrument $n$ is defined by the ratio of the wavelength adjusted absorption coefficients divided by the average of the absorption coefficients measured with the MAAP.

$\varepsilon^{n}=\sigma_{\text {ap }}^{n}(637 \mathrm{~nm}) / \operatorname{avg}\left[\sigma_{\text {ap }}^{\text {MAAP }}(637 \mathrm{~nm})\right]$

Relative sensitivities for PSAPs and Aethalometers were averaged for instruments of the same type and wavelength. Average sensitivities and unit to unit variabilities are given in Table 10.

\subsubsection{Relative sensitivities of PSAP}

As an example, Fig. 6 shows absorption coefficients measured during GAW2005 with $3 \lambda$-PSAP without wavelength adjustment vs. those measured with MAAP. To avoid effects of "overloading" of the PSAP filter, data were only used when the transmittance was between 1.0 and 0.7. Throughout the manuscript, fits were forced through zero. Fits with slope and intercept would complicate discussions. Additionally no better insight in the physics of the instruments can be achieved from slope and intercept. Data evaluation of GAW2005 showed a lower sensitivity of PSAPs compared to the MAAP. The relative sensitivities for the three wavelengths are $0.77,0.79$, and 0.79 after adjusting the PSAP data to the MAAP wavelength of $637 \mathrm{~nm}$. The relative sensitivity of the single wavelength PSAP was 0.86. Uncertainties of the sensitivites are $7 \%$ and $27 \%$ for both types of PSAP, respectively.
Table 10. Relative sensitivities of Aethalometer and PSAP compared to MAAP for ambient aerosol. Absorption coefficients were adjusted to $637 \mathrm{~nm}$ using average Ångström exponents. The uncertainty is calculated from the unit to unit variability of the instruments. Correction methods are Bond (Bond et al., 1999) for PSAPs and Weingartner (Weingartner et al., 2003) for Aethalometers.

\begin{tabular}{lll}
\hline Instrument & $\sigma_{\mathrm{ap}}^{n} / \sigma_{\mathrm{ap}}^{\mathrm{MAAP}}$ & Workshop \\
\hline $3 \lambda$-PSAP, 650 nm & $0.79 \pm 0.07$ & GAW2005 \\
$1 \lambda$-PSAP, 585 nm & $0.86 \pm 0.27$ & GAW2005 \\
Aethalometer, 660 nm & $1.37 \pm 0.11$ & GAW2005 \\
Aethalometer, white light & $1.21^{1}$ & GAW2005 \\
\hline $3 \lambda$ and $1 \lambda$-PSAPs & & \\
Exp.1 & $1.05 \pm 0.08$ & EUSAAR2007 \\
Exp.2 & $0.99 \pm 0.10$ & EUSAAR2007 \\
Aethalometer 660 nm & $1.6 \pm 0.20$ & EUSAAR2007 \\
\hline
\end{tabular}

${ }^{1}$ For the wavelength adjustment to $637 \mathrm{~nm}$ it is assumed that effective wavelength is $840 \mathrm{~nm}$.

During EUSAAR2007 the relative sensitivities for two experiment runs were 1.05 and 0.99 and the corresponding uncertainties are $8 \%$ and $10 \%$, respectively. The correlation of absorption coefficients adjusted to $637 \mathrm{~nm}$ is shown in Fig. 7 for one run. The sensitivity for low loadings (transmittance between 1 and 0.7 ) is 1.03 and for higher loading (transmittance smaller 0.7 ) the sensitivity is 0.96 . Reduced sensitivity at higher loading implies that the applied Bond loading correction, that accounts for the reduction of the optical path length in the filter with increasing filter load, is not sufficient for transmittance smaller than 0.7. There seems to be a coincidence of high loadings and high absorption coefficients. The coincidence is caused by circumstances of the measurement and has no physical meaning.

\subsubsection{Relative sensitivities of Aethalometer}

The Weingartner correction requires the single scattering albedo (cf. Sect. 4.3), which was calculated from MAAPs and nephelometer $637 \mathrm{~nm}$. Single scattering albedos were on average 0.91 and 0.81 for GAW2005 and EUSAAR2007. Absorption coefficients from Aethalometer using the Weingartner correction are higher than the reference absorption from MAAP. Figure 8 shows an example of absorption coefficient measured by Aethalometer at $660 \mathrm{~nm}$ versus the absorption coefficient measured by MAAP at $637 \mathrm{~nm}$. Relative sensitivities are $1.6 \pm 0.2$ and $1.37 \pm 0.1$ for EUSAAR2007 and GAW2005, respectively. As mentioned before in this paper the $C$ value found by Weingartner et al. (2003) is rather low. Collaud Coen et al. (2009) compared MAAP and Aethalometers at several field sites in Europe and also found higher $C$ values in the range from 2.9 to 4.3. Application of $C$ values in that range would lead to sensitivities closer to unity. The value $C=2.14$, we used 


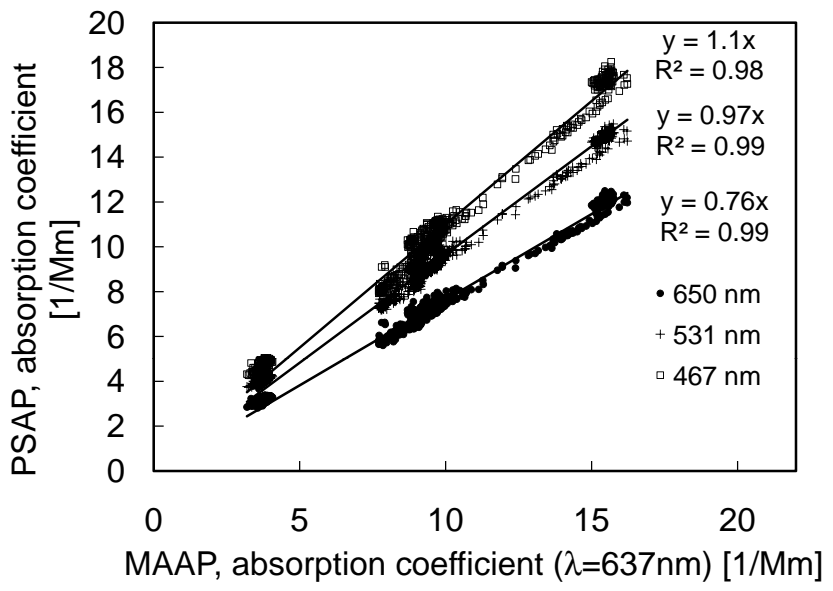

Fig. 6. Ambient air runs during GAW2005. PSAP absorption coefficients vs. MAAP absorption coefficients $(637 \mathrm{~nm})$ for the three PSAP wavelengths. The linear regression is forced through the origin. PSAP data were corrected using the Bond correction.

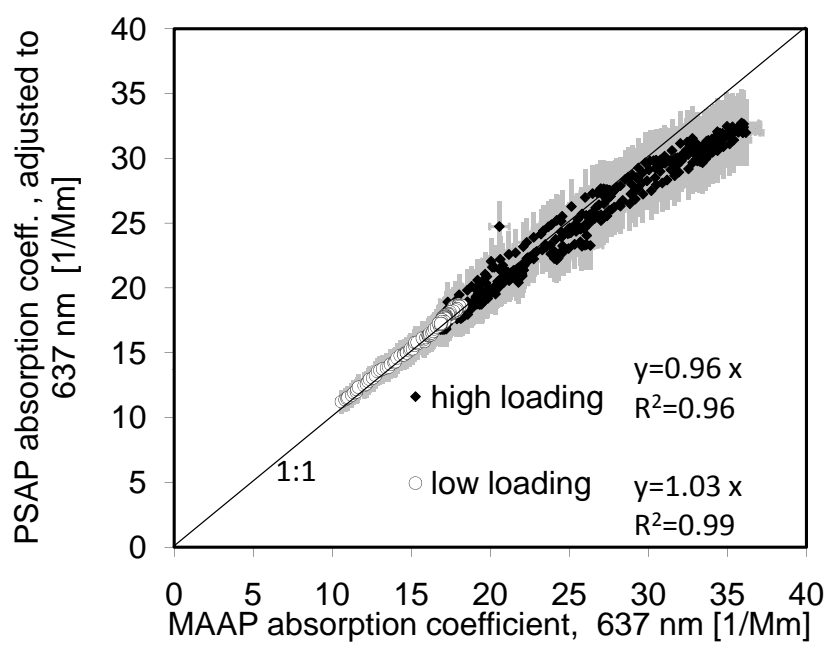

Fig. 7. Ambient air Exp. 2 during the EUSAAR2007 workshop. PSAP absorption coefficients adjusted to $637 \mathrm{~nm}$ vs. MAAP absorption coefficients at $637 \mathrm{~nm}$. The error bars represent the unit to unit variability of $3 \%$ and $8 \%$ for the MAAP and the PSAP, respectively. Data points for low loading are for data with PSAP transmittance between 1.0 and 0.7 ; high loading is for data with PSAP transmittance between 0.7 and to 0.2 .

for our data evaluation, was determined for experiments with pure soot (Weingartner et al. 2003). Higher $C$ values were found in the AIDA experiments (Saathoff et al., 2003) when secondary organic aerosol was also present in the chamber.

The determination of the light absorption coefficient with AE10 Aethalometers is difficult because of the ill-defined spectral sensitivity. However, for the sake of intercomparability, we applied the Weingartner correction and adjusted the absorption coefficient to $637 \mathrm{~nm}$ by adopting the effective

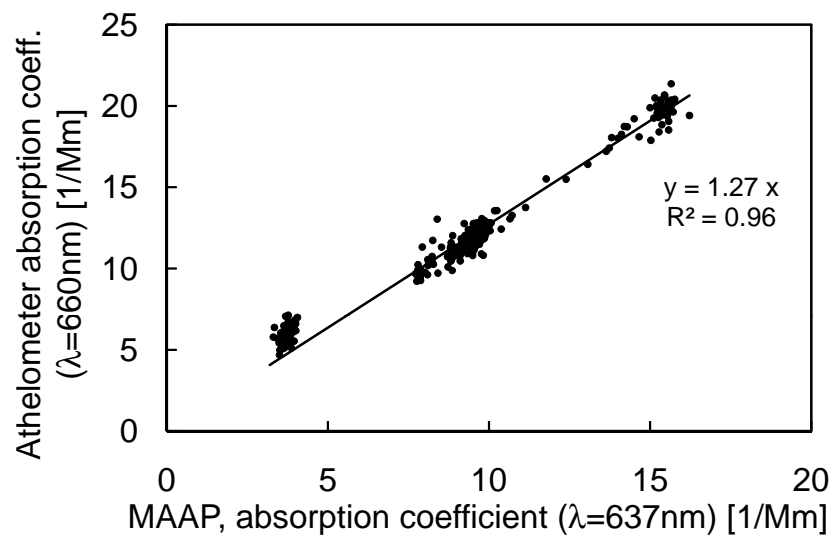

Fig. 8. Ambient air runs during GAW2005. Aethalometer (model AE31, $660 \mathrm{~nm}$ ) absorption coefficient vs. MAAP absorption coefficient $(\lambda=637 \mathrm{~nm})$. Aethalometer data were corrected using Weingartner et al. (2003).

wavelength for white light Aethalometers as specified by Weingartner et al. (2003). The so-obtained relative sensitivity of AE10 was 1.21 during GAW2005.

\subsubsection{Summary of experiments with ambinet air}

Relative sensitivities differ strongly between GAW2005 and EUSAAR2007 (cf. Table 10). For GAW2005 the relative sensitivities are significantly smaller for both PSAP and Aethalometer. Absorption coefficients were in a moderate range from 8 to $15 \mathrm{Mm}^{-1}$ (GAW2005) and from 12 to $23 \mathrm{Mm}^{-1}$ (EUSAAR2007). For EUSAAR2007 and GAW2005 differences in the particle number size distribution (cf. Figs. 2 and 3) were observed, which could be an indication of different particle composition and thus optical properties. The sensitivity to e.g. organic carbon is not well understood (e.g. Lack et al., 2008) and can differ between PSAP, MAAP, and Aethalometer. Thus an artifact due to organics is possible but not proven. Besides, differences in the particle composition and number size distribution, we do not have an explanation for the different sensitivities between both workshops.

\subsubsection{Unit to unit variabilities and noise during ambient air experiments}

Figure 9 shows the unit to unit variability of corrected absorption coefficients for MAAP, PSAP, and Aethalometer versus reference absorption (average of absorption coefficients measured by MAAPs). When comparing values for PSAP, MAAP, and Aethalometer, it should be considered, that the scaling in Fig. 9a-c differs. Values are shown for 1 and 10 min averaging times for MAAP and PSAP. The slope of linear regressions indicate that the MAAP has lower unit to unit variability with $3.2 \%$ and $3.8 \%$ compared to the unit to unit variability of PSAP of about $8 \%$. For both types 

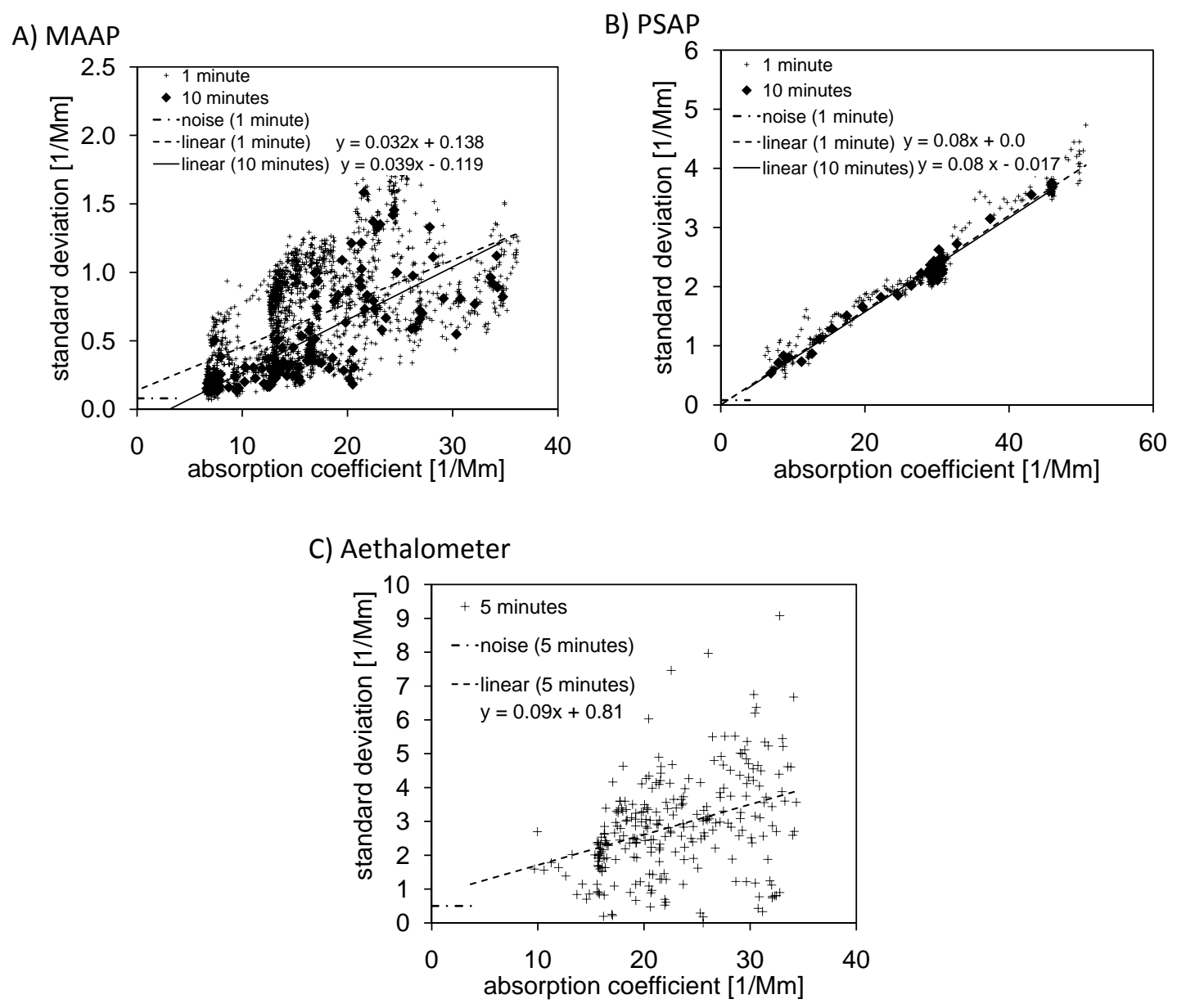

Fig. 9. EUSAAR2007: Unit to unit variability (standard deviation of several instruments) vs. absorption coefficient for (a) MAAP (seven instruments), (b) PSAP (six $3 \lambda$-PSAP, green) and (c) Aethalometer (four $7 \lambda$-Aethalometers, $660 \mathrm{~nm}$ ). PSAP and MAAP data are shown for the highest time resolution of one minute and for an averaging time of ten minutes. Aethalometer data are shown for an averaging time of $5 \mathrm{~min}$. The noise level is indicated as horizontal line.

of instruments the standard deviation does not depend on averaging time. Thus the averaging time should be considered when absorption coefficients are smaller or similar to the instrumental noise. For absorption coefficients much larger than the noise, the precision of the instruments is dominated by unit to unit variability (systematic error) and not by noise (statistical error). The regression line for the Aethalometer has a similar slope $8.9 \%$ as the PSAP but the points spread much more compared to the PSAP. The noise of the Aethalometer is about $0.3 \mathrm{Mm}^{-1}$ ( 3 min averaging time) compared to $0.08 \mathrm{Mm}^{-1}$ for PSAP (1 min averaging time). Only a part of the larger spreading can be explained by the instrumental noise. A possible interpretation of this plot could be, that there is an additional source of statistical errors, which probably increases with increasing absorption coefficients. We can not state, if this noise characteristics affects the uncertainties of ambinet air measurements until a sound explanation for this behaviour is found.

\subsection{Ammonium sulfate}

Uncertainties in the absorption caused by particle scattering are an important matter. For example, the bias in absorption coefficients due to particle scattering is about $1.6 \% \pm 1.6 \%$ (Bond et al., 1999) of the scattering coefficient for PSAP. The uncertainty of absorption coefficients caused by the uncertainty of the scattering correction depends on the single scattering albedo. For example, for PSAP the resulting uncertainty in absorption coefficients is $14 \%$ and $30 \%$ at single scattering albedos of 0.9 and 0.95 , respectively, The sensitivity of the PSAP, Aethalometer and MAAP absorption photometers to particle scattering was investigated during GAW2005 and using ammonium sulfate. Size distributions and optical properties of this aerosol are presented in Sect. 3. 


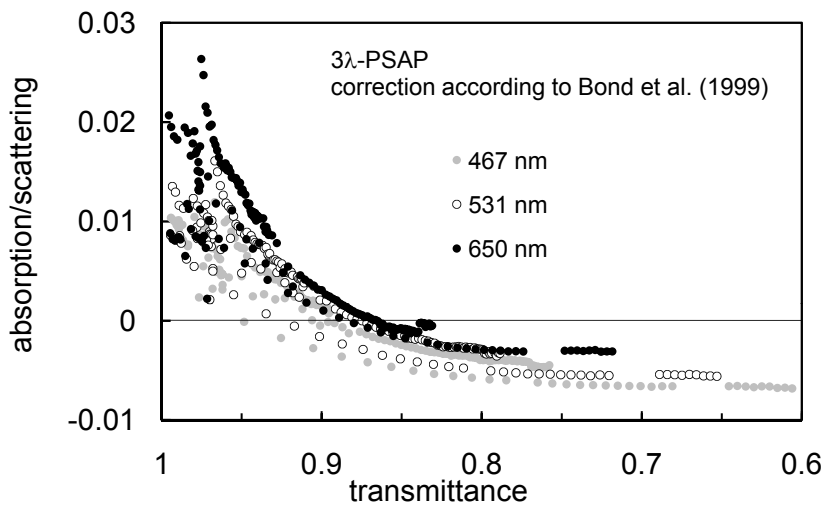

Fig. 10. Remaining cross sensitivity of absorption to particle scattering as a function of filter transmittance for the $3 \lambda$-PSAP. Absorption coefficients were corrected using Bond et al. (1999).

\subsubsection{PSAP}

The cross sensitivity to particle scattering is defined as the corrected absorption coefficients divided by the scattering coefficient. The scattering coefficient was interpolated from adjacent wavelengths and, to be consistent with Bond et al. (1999), no truncation correction was applied to nephelometer data. Bond et al. (1999) derived a cross sensitivity of about $1.6 \% \pm 1.6 \%$. Virkkula et al. (2005) determined the cross sensitivity for a $3 \lambda$-PSAP to be between $1.5 \%$ and $2.5 \%$, and for a $1 \lambda$-PSAP to be $2.3 \%$. The uncertainty is lower compared to Bond et al. (1999) and amounts about $0.3 \%$. In view of the large uncertainties these values are in agreement with Bond et al. (1999).

For the GAW2005 workshop three $1 \lambda$-PSAPs still showed a sensitivity between $0.89 \%$ and $2.18 \%$, whereas two $3 \lambda$ PSAPs showed a sensitivity between $0.16 \%$ and $0.89 \%$. These large differences among different instruments and experiments reflect the large uncertainty already given by Bond et al. (1999). Experiments during EUSAAR2007 were designed to provide insight into the loading dependence of the sensitivity to particle scattering. Filters were loaded with ammonium sulfate as long as needed to have a significant change in transmittance. In most experiments the transmittance was smaller than 0.7 , for at least one wavelength of the photometer. Figure 10 shows the sensitivity vs. transmittance for two experiments with a $3 \lambda$-PSAP. The Bond correction underestimates the sensitivity to scattering for low loadings, and for higher loadings (transmittance smaller than $\sim 0.9$ ) an over-correction occurs. The remaining span of sensitivities from $+2.5 \%$ to $-0.5 \%$ almost explains the large uncertainty in the scattering correction given by Bond et al. (1999) and was also seen during the GAW2005 workshop. It can also be seen that the cross sensitivity to scattering increases with increasing wavelength.

An obvious problem in the correction given by Bond et al. (1999) is the lack of an explicit loading correction for non

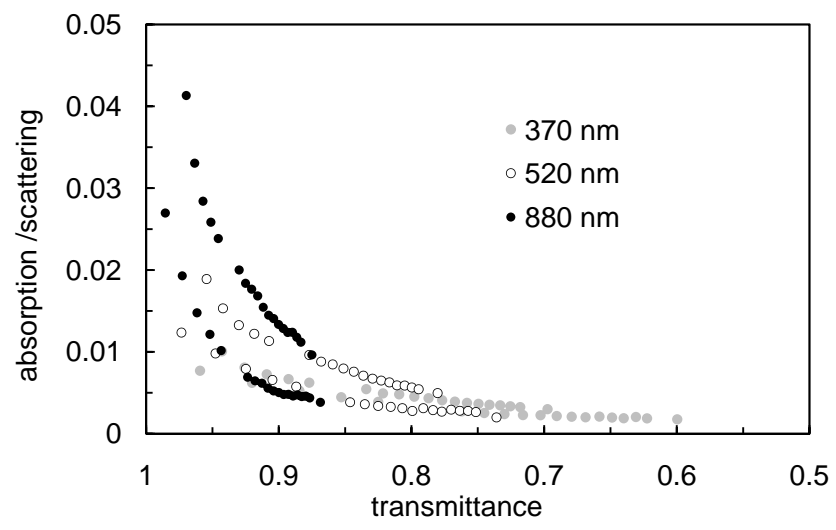

Fig. 11. Sensitivity to particle scattering as a function of filter transmittance for the $7 \lambda$-Aethalometer. Shown are the ratios of absorption coefficients divided by scattering coefficients for three wavelengths. Absorption coefficients were corrected using Weingartner et al. (2003).

absorbing aerosols. The loading correction, which was derived for strongly absorbing aerosols, is applied to measured attenuation. That means, that loading effects for absorbing as well as scattering particles were corrected with the same loading correction function.

\subsubsection{Aethalometer}

The first investigation of the sensitivity to particle scattering for the Aethalometer was published by Weingartner et al. (2003) who obtained ratios for $\sigma_{\text {ATN }} / \sigma_{\text {sp }}$ of $0.7 \%$ and $0.6 \%$ for ammonium sulfate for wavlengths $470 \mathrm{~nm}$ and $660 \mathrm{~nm}$, respectively.

During GAW2005 and EUSAAR2007 experiments for multi-wavelength Aethalometers were performed. White light Aethalometers were not used for this experiment because of their larger noise. Cross sensitivities for Aethalometers are presented in Table 11. Absorption coefficients were corrected according to Weingartner et al. (2003) and scattering coefficients, measured by a nephelometer were adjusted to the wavelengths of Aethalometers. For experiments during GAW2005 the cross sensitivity to scattering ranges between $1.57 \%$ and $2.67 \%$ in the wavelength range $470-660 \mathrm{~nm}$, what is significantly higher than the values derived by Weingartner et al. (2003) and more comparable to the cross sensitivities measured for PSAP. One possible reason for differences compared to other studies might be found in the particle size distribution and different ranges of particle loading, but cannot be explained satisfactorily. Similar results can be found for EUSAAR2007. As an example, Fig. 11 shows the cross sensitivity versus the transmittance. The apparent absorption decreases with increasing loading. Also a dependence on wavelength can be seen. The cross sensitivity ranges from $3.5 \%$ to $0.5 \%$. This range of values is larger than that observed for PSAP. However, if a similar wavelength range 
Table 11. Response to ammonium sulfate at GAW2005. PSAP and Aethalometer data were corrected following Bond et al. (1999) and Weingartner (2003), respectively, to show the remaining cross sensitivity to particle scattering.

\begin{tabular}{|c|c|c|}
\hline Instrument and $S / N$ & $\begin{array}{r}\text { wavelength } \\
{[\mathrm{nm}]}\end{array}$ & $\begin{array}{c}\text { relative apparent } \\
\text { absorption }[\%] \text {, } \\
\left(\sigma_{\mathrm{ap}} / \sigma_{\mathrm{sp}}\right) \times 100\end{array}$ \\
\hline MAAP 049 & 637 & 0.69 \\
\hline MAAP 01A & 637 & 0.65 \\
\hline MAAP 050 & 637 & 0.63 \\
\hline MAAP 013 & 637 & 0.62 \\
\hline MAAP 030 & 637 & 0.63 \\
\hline MAAP 032 & 637 & 0.51 \\
\hline PSAP 20B & 585 & 1.72 \\
\hline PSAP 071 & 530 & 0.89 \\
\hline PSAP 20A & 585 & 2.18 \\
\hline PSAP 90A & 467 (B) & 0.34 \\
\hline PSAP 90A & $531(\mathrm{G})$ & 0.42 \\
\hline PSAP 90A & $650(\mathrm{R})$ & 0.52 \\
\hline PSAP 90B & 467 (B) & 0.16 \\
\hline PSAP 90B & $531(\mathrm{G})$ & 0.42 \\
\hline PSAP 90B & $650(\mathrm{R})$ & 0.89 \\
\hline PSAP 048 & 585 & 1.64 \\
\hline \multirow[t]{7}{*}{ Aeth. 483} & 370 & 1.14 \\
\hline & 470 & 1.63 \\
\hline & 520 & 1.79 \\
\hline & 590 & 2.12 \\
\hline & 660 & 2.53 \\
\hline & 880 & 4.86 \\
\hline & 950 & 4.74 \\
\hline \multirow[t]{7}{*}{ Aeth. 563} & 370 & 1.30 \\
\hline & 470 & 1.61 \\
\hline & 520 & 2.67 \\
\hline & 590 & 2.57 \\
\hline & 660 & 2.09 \\
\hline & 880 & 5.06 \\
\hline & 950 & 5.47 \\
\hline \multirow[t]{2}{*}{ Aeth. 426} & 370 & 0.95 \\
\hline & 880 & 3.97 \\
\hline \multirow[t]{7}{*}{ Aeth. 337} & 370 & 1.14 \\
\hline & 470 & 1.58 \\
\hline & 520 & 1.57 \\
\hline & 590 & 1.96 \\
\hline & 660 & 1.99 \\
\hline & 880 & 2.42 \\
\hline & 950 & 2.81 \\
\hline
\end{tabular}

is considered for PSAP and Aethalometers, thus excluding the Aethalometer UV and near infrared channels, the span of cross sensitivities reduces to $2.0 \%$ to $0.5 \%$, which is similar to values observed for PSAP.

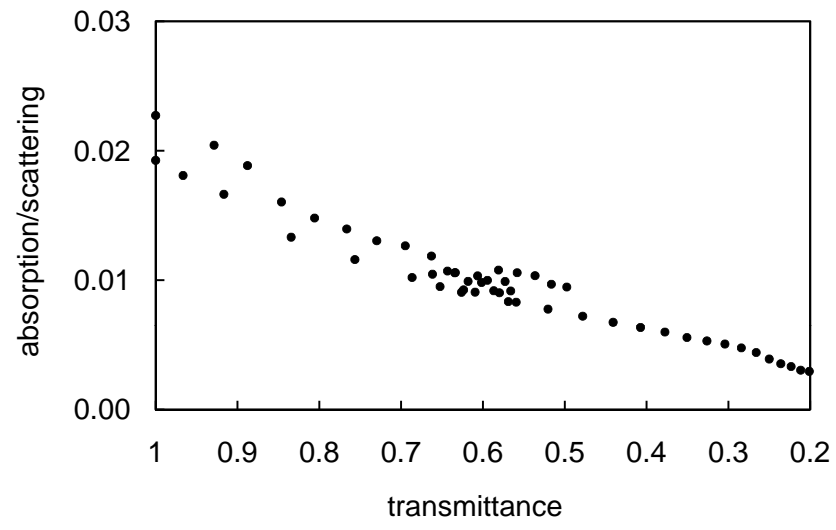

Fig. 12. Cross sensitivity of absorption to particle scattering as a function of filter transmittance for MAAP.

\subsubsection{MAAP}

Data of MAAP were corrected internally by a radiative transfer model described in Petzold et al. (2004). Petzold et al. (2005) showed that for MAAP the remaining cross sensitivity to non absorbing aerosol is smaller than $3 \%$.

For GAW2005 the cross sensitivity to particle scattering is on average $0.62 \%$ with a standard deviation (unit to unit variability) of $0.06 \%$ for six MAAPs. This value is significantly smaller than values reported by Petzold et al. (2005). For EUSAAR a loading dependend cross sensitivity was measured. Figure 12 shows the cross sensitivity to scattering versus transmittance. The cross sensitivity covers a range from $3 \%$ to $0 \%$. Within this range, the cross sensitivities given by Petzold et al. (2005) and measured during the GAW2005 workshop are in agreement.

\subsubsection{Summary of measurements with ammonium sulfate}

The measurements done during both workshops and results reported in literature show, that there is still a lack of understanding the problem of the cross sensitivity to particle scattering. The experiments done during GAW2005 and EUSAAR2007 clearly show that a specific loading correction for scattering particles is needed. Additionally all multi-wavelength photometers show that the sensitivity to scattering increases with increasing wavelength. For the Aethalometer, the sensitivity to non-absorbing aerosols is about four times higher for the IR-wavelength $(950 \mathrm{~nm})$ than for the UV-wavelength $(350 \mathrm{~nm})$. Wavelength dependencies of scattering corrections also were found in Arnott et al. (2005) for Aethalometer and Virkkula et al. (2005) for PSAP.

Until now, there is no physics-based model which can explain wavelength and loading dependencies. A deeper discussion requires radiative transfer modeling of filter-based measurements (e.g. Moteki et al., 2010). 
A further point worth mentioning is the problem of preloading of the filter. Preloading is defined here as the situation where particles have been collected on the filter before the start of the measurements when the transmittance is set to unity. It can easily be seen (Fig. 11) that the cross sensitivity to particle scattering is very sensitive to the loading state, and to the transmittance of the filter. To our knowledge, this is the first time that this problem has been reported. It is hard to compare results from different experiments without having proof that filters were clean before the experiment. The authors worked out these findings after the EUSAAR2007 workshop. Thus it is also possible, that data presented in this paper suffer from an undefined preloading of filters. It would be desirable to perform experiments taking into account the problems with preloaded filters.

\subsection{Soot}

Carbon black (Printex 75, Evonik Degussa GmbH) is the product of incomplete combustion of hydrocarbons. For Printex 75 the primary particle size is about $17 \mathrm{~nm}$ and less than $1 \%$ of the composition are dyes and organic compounds. Size distribution and average optical properties measured during GAW2005 are given in Sect. 3.

Because of technical and experimental problems during EUSAAR2007 these data were not used for further data analysis. Here we present result of the GAW2005 workshop. MAAP was chosen to be the reference instrument. Results are summerized in Table 12.

The relative response was calculated for each wavelength after adjusting the wavelength to that of MAAP. Single wavelength PSAPs showed an average sensitivity of 1.03 , whereas the values range from 0.95 to 1.1 . The sensitivity of $3 \lambda$ PSAP was $0.84,0.83$ and 0.80 at wavelengthes 460,530 , and $650 \mathrm{~nm}$, respectively. Differences between $1 \lambda$-PSAPs and $3 \lambda$-PSAPs are larger than for ambinet air experiments during GAW2005 with sensitivities of 0.79 and 0.86 , repectively. Here we would like to remind the reader, that there was no large different between the two types of PSAPs during EUSAAR, and relative sensitivities were determined to be 0.99 and 1.05 for two ambient air experiments.

Two $7 \lambda$-Aethalometers (after the Weingartner correction) showed very different responses. For one instrument, the response for in the wavelength range $470-880 \mathrm{~nm}$ was between 2.1 and 2.2, and the other instrument had a significantly lower response ranging from 1.49 to 1.53 . Differences between the two Aethalometers are larger than the unit to unit variability of about $20 \%$ at wavelength $660 \mathrm{~nm}$. Corrections are based on a $C$ value of 2.14. As mentioned before, this value is lower than values found by Collaud Coen et al. (2010).

Differences between the absorption measured by the MAAP, PSAP and Aethalometer cannot be explained. Possible reasons could be the different approaches used for correction and different aerosols during calibration. For details
Table 12. Relative responses to carbon black. PSAP and Aethalometer data were corrected according to Bond et al. (1999) and Weingartner et al. (2003). Wavelengths were adjusted to $637 \mathrm{~nm}$.

\begin{tabular}{lcc}
\hline \multicolumn{3}{c}{ Workshop GAW2005 } \\
\hline Instrument and $S / N$ & Wavelength/nm & $\begin{array}{c}\text { Wavelength adjusted relative } \\
\text { sensitivity } \sigma_{\text {ap }} / \sigma_{\text {ap }}^{\text {MAAP }}\end{array}$ \\
\hline PSAP 20B & 565 & 1.05 \\
PSAP 48 & 565 & 0.94 \\
PSAP 71 & 530 & 1.1 \\
PSAP 90B & 460 & 0.84 \\
& 530 & 0.83 \\
& 650 & 0.8 \\
\hline Aeth. 337 & 370 & 2.6 \\
& 470 & 2.13 \\
& 520 & 2.1 \\
& 590 & 2.11 \\
& 660 & 2.11 \\
& 880 & 2.15 \\
& 950 & 2.22 \\
\hline Aeth. 483 & 370 & - \\
& 470 & 1.52 \\
& 520 & 1.49 \\
& 590 & 1.51 \\
& 660 & 1.53 \\
& 880 & 1.53 \\
& 950 & - \\
\hline
\end{tabular}

of the calibration experiments we refer to Bond et al. (1999), Weingartner et al. (2003), and Petzold et al. (2004).

\section{Summary and conclusions}

We have presented a characterization of the PSAP, MAAP, and Aethalometer with respect to effective wavelength, spot area size, unit to unit variabilities, instrumental noise, and relative sensitivity to absorbing and non absorbing aerosol particles. Results from two absorption photometer workshops are discussed and compared to values given in literature and user manuals of instruments.

Corrections applied to the photometer were Bond et al. (1999) for PSAP, and Weingartner et al. (2003) with a constant $C=2.14$ for Aethalometer. For simplifications only these corrections were used, although more corrections schemes for PSAP and Aethalometer can be found in literature. For MAAP a correction of 5\% was applied, to account for an adjustment of wavelengths. The emission wavelengths of photometers showed, that those of the Aethalometer agree with values given by the manufacturer. The actual wavelength of the MAAP is $637 \mathrm{~nm}$ instead of $670 \mathrm{~nm}$ as specified by the manufacturer. Consequently, absorption coefficients reported by the MAAP should be multiplied by a factor of 1.05 to obtain the absorption coefficient at a wavelength 
of $637 \mathrm{~nm}$. The emission wavelength of the commercial single wavelength PSAP was determined to be $585 \mathrm{~nm}$. One newer single wavelength instruments had a wavelength of $522 \mathrm{~nm}$, and wavelengths for three wavelength PSAPs were 467, 531 and $650 \mathrm{~nm}$. Two custom made single wavelength PSAPs had a wavelength of $532 \mathrm{~nm}$.

Measurement of spot sizes showed, that for MAAP there is no significant variation between different instruments. For PSAP and Aethalometer spot sizes can differ up to $6 \%$ and $8 \%$ from the nominal value. Since spot size and flow rate are used for calculating the absorption coefficient, the unit to unit variability depends on spot size and flow. We recommend to measure regularly spot size and flow rate. For all three types of absorption photometers we recommend to operate the instruments within the specifications for flow. After recalibrating flows, the unit to unit variability, determined with ambient air, for $1 \lambda$ PSAPs and $3 \lambda$ PSAPs was $27 \%$ and $8 \%$ respectively. For PSAP, also a spot size correction was applied. Aethalometer unit to unit variabilities are up to $20 \%$. MAAPs showed a variability of $3 \%$.

The MAAP showed instrumental noise levels of $0.08 \mathrm{Mm}^{-1}$ and $0.22 \mathrm{Mm}^{-1}$ for a one minute averaging time during the GAW2005 and EUSAAR2007 workshops, respectively. Noise levels for the $3 \lambda$ PSAP determined with a one minute averaging time were similar for both workshops and were in the range from $0.05 \mathrm{Mm}^{-1}$ to $0.07 \mathrm{Mm}^{-1}$. In contrast, single wavelength PSAPs showed larger noise with average values of 0.36 and 0.15 derived during GAW2005 and EUSAAR2007, respectively. Aethalometer noise strongly depends on the wavelength. With an averaging time of three minutes, the noise of the AE31 Aethalometer at wavelengths of 370 and $880 \mathrm{~nm}$ was $0.42 \mathrm{Mm}^{-1}$ and $0.17 \mathrm{Mm}^{-1}$ (GAW2005). During EUSAAR2007, the Aethalometer noise was estimated for Aethalometers with ER and HS spot sizes to be $0.8 \mathrm{Mm}^{-1}$ and $0.38 \mathrm{Mm}^{-1}$, respectively. It should be noted, that the noise depends and flow rate, spot size, and averaging time.

The relative sensitivity for ambient aerosol of the PSAP compared to the MAAP was 0.8 for $3 \lambda$-PSAP and 0.86 for $1 \lambda$-PSAP during GAW2005. $1 \lambda$ - and $3 \lambda$-PSAPs showed no significant difference. During EUSAAR2007, average sensitivities of PSAPs were between 0.99 and 1.05 for two independent experiments. Aethalometer relative sensitivities for the $660 \mathrm{~nm}$ channel were on average 1.37 and 1.6 for GAW2005 and EUSAAR2007, respectively.

Relative sensitivity to non absorbing aerosol has been determined from measurements with ammonium sulfate. An average scattering cross sensitivity of $1.6 \%$ is included in the Bond-correction. The remaining cross sensitivity to scattering was on average $0.62 \%$ during GAW2005. For PSAP the cross sensitivity was on average $0.45 \%$ for $3 \lambda$ PSAPs at all wavelengths and $1.08 \%$ for $1 \lambda$-PSAPs. During EUSAAR2007, a loading and wavelength dependence has been observed. Cross sensitivities for low loadings (transmittance close to unity) were between $2 \%$ and $2.7 \%$. With decreasing transmittance, the cross sensitivity became negative $(-0.5 \%)$. Thus the Bond correction underestimates the cross sensitivity at low loading (transmittance $>0.9$ ) and overestimates it at higher loadings.

The cross sensitivity of MAAP was between $0.5 \%$ and $0.69 \%$ during GAW2005. A loading dependent investigation during EUSAAR2007 showed average values for the cross sensitivity of $2.6 \%$ at a transmittance of unity and about $1 \%$ at a transmittance of 0.7 .

For Aethalometer a wavelength dependence was observed during EUSAAR2007. At $370 \mathrm{~nm}$ and $880 \mathrm{~nm}$ the cross sensitivities were on average $1.2 \%$ and $4.3 \%$, respectively. A loading dependence was also observed during EUSAAR2007. At high transmittances $(>0.96)$ the cross sensitivity reached $4.5 \%$ at a wavelength of $880 \mathrm{~nm}$, which decreased to $1 \%$ at a transmittance of 0.8 . For a wavelength range similar to that of PSAP, thus excluding the Aethalometer UV and near infrared channels, the span of sensitivities for Aethalometers reduces to $2.5 \%$ to $+0.5 \%$, which is similar to the range observed for PSAP.

Future calibration or intercomparison experiments would benefit from experiments with physically well characterized absorption standards. In Lack et al. (2009) it was shown that absorption standards, e.g. polystyrene spheres, could serve as absorption standards. A dependence of the response of PSAP to particle size was shown by Lack et al. (2009) and Nakayama et al. (2010) using polystyrene spheres and nigrosin, respectively. The magnitude of the size dependence can be different for PSAP, MAAP, and Aethalometer, what complicates comparison of the relative responses to MAAP. Size effects are critical in many respects. The sensitivity of long-term measurements of aerosol light absorption can be affected by changes of the size of the absorbing particle fraction. Also, the applied method of correction is referenced to particles used during calibration experiments. The sensitivity to organics was investigated in Lack et al. (2008). To our knowledge a comprehensive investigation concerning the sensitivity of filter based measurements to organics in ambient air is missing.

The authors wish to state that reference to a particular manufacturer or company in this paper is not an endorsement of the particular manufacturer or company.

Acknowledgements. The work described in this paper was supported by the EU FP6 Integrated Infrastructures Initiatives (I3) project EUSAAR (European Supersites for Atmospheric Aerosol Research, project FP6-026140), with the EU FP6 Network of Excellence ACCENT (Atmospheric Composition Change: a European Network, project GOCE-CT-2004-505337) and the WMO GAW (Global Atmosphere Watch) program.

Edited by: M. Wendisch 


\section{References}

Anderson, T. L. and Ogren, J. A.: Determining aerosol radiative properties using the TSI 3563 integrating nephelometer, Aerosol Sci. Tech., 29, 57-69, 1998.

Anderson, T. L., Covert, D. S., Marshall, S. F., Laucks, M. L., Charlson, R. J., Waggoner, A. P., Ogren, J. A., Caldow, R., Holm, R. L., and Quant, F. R., Sem, G. J., Wiedensohler, A., Ahlquist, N. A., and Bates, T. S.: Performance Characteristics of a HighSensitivity, Three-Wavelength, Total Scatter/Backscatter Nephelometer, J. Atmos. Ocean. Tech., 13(5), 967-986, 1996.

Anderson, T. L., Covert, D. S., Wheeler, J. D., Harris, J. M., Perry, K. D., Trost, B. E., Jaffe, D. J., and Ogren, J. A.: Aerosol backscatter fraction and single scattering albedo: Measured values and uncertainties at a coastal station in the Pacific Northwest, J. Geophys. Res., 104(D21), 26793-26807, 1999.

Andreae, M. O.: The dark side of Aerosols, Nature, 409, 671-672, 2001.

Ansmann, A., Wandinger, U., Wiedensohler, A., and Leiterer, U.: Lindenberg Aerosol Characterization Experiment 1998 (LACE 98): Overview, J. Geophys. Res., 107(D21), 8129, doi:10.1029/2000JD000233, 2002.

Arnott, W. P., Hamasha, K., Moosmüller, H., Sheridan, P. J., and Ogren, J. A.: Towards aerosol light-absorption measurements with a 7-wavelength aethalometer: Evaluation with a photoacoustic instrument and 3-wavelength nephelometer, Aerosol Sci. Tech., 39, 17-29, 2002.

Bates, T. S., Huebert, B. J., Gras, J. L., Griffiths, F. B., and Durkee, P. A.: International Global Atmospheric Chemistry (IGAC) Project's First Aerosol Characterization Experiment (ACE 1): Overview, J. Geophys. Res., 103(D13), 16297-16318, 1998.

Bond, T. C., Anderson, T. L., and Campbell, D.: Calibration and intercomparison of filter-based measurements of visible light absorption by aerosols, Aerosol Sci. Tech., 30, 582-600, 1999.

Bond, T. C., Covert, D. S., and Müller, T.: Truncation and Angular Scattering Corrections for Absorbing Aerosols in the TSI 3563 Nephelometer, Aerosol Sci. Tech., 43, 866-871, doi:10.1080/02786820902998373, 2009.

Cappa, C. D., Lack, D. A., Burkholder, J. B., and Ravishankara, A. R.: Bias in filter-based aerosol light absorption measurements due to organic aerosol loading: Evidence from laboratory measurements, Aerosol Sci. Tech., 42, 1022-1032, doi:10.1080/02786820802389285, 2008.

Charlson, R. J., Langner, J., Rodhe, H., Leovy, C. B., and Warren, S. G.: Perturbation of the northern hemisphere radiative balance by backscattering from anthropogenic sulfate aerosols, Tellus AB, 43, 152-163, 1991.

Collaud Coen, M., Weingartner, E., Apituley, A., Ceburnis, D., Fierz-Schmidhauser, R., Flentje, H., Henzing, J. S., Jennings, S. G., Moerman, M., Petzold, A., Schmid, O., and Baltensperger, U.: Minimizing light absorption measurement artifacts of the Aethalometer: evaluation of five correction algorithms, Atmos. Meas. Tech., 3, 457-474, doi:10.5194/amt-3-457-2010, 2010.

Gerber, H. E.: Optical Techniques for the measurement of light absoption by particulates, in: Particulate Carbon, Atmospheric Life Cycle, edited by: Wolff, G. T. and Klimisch, R., Plenum Press, New York, 1982.

Hansen, A. D. A.: The Aethalometer, available at: http://mageesci. com/support/downloads/Aethalometer_book_2005.07.03.pdf (last access: December 2010), 2005.
Hansen, A. D. A., Rosen, H., and Novakov, T.: The aethalometer - an instrument for the real-time measurement of optical absorption by aerosol particles, Sci. Total Environ., 36, 191-196, 1984.

Hansen, J., Sato, M., and Ruedy, R.: Radiative forcing and climate response, J. Geophys. Res., 102(D6), 6831-6864, 1997.

Heintzenberg, J.: The SAMUM-1 experiment over Southern Morocco: overview and introduction, Tellus B, 61, 2-11, 2009.

Heintzenberg, J., Wiedensohler, A., Tuch, T. M., Covert, D. S., Sheridan, P. J., Ogren, J. A., Gras, J., Nessler, R., Kleefeld, C., Kalivitis, N., Aaltonen, V., Wilhelm, R.-T., and Havlicek, M.: Intercomparisons and aerosol calibrations of 12 commercial integrating nephelometers of three manufacturers, J. Atmos. Ocean. Tech., 23, 902-914, 2006.

Intergovernmental Panel on Climate Change (IPCC): Climate Change 2001: The Scientific Basis, Contribution of Working Group I to the Third ASSESMENT report of the IPCC, Cambridge University Press, New York, 2001.

Kulmala, M., Asmi, A., Lappalainen, H. K., Carslaw, K. S., Pöschl, U., Baltensperger, U., Hov, Ø., Brenquier, J.-L., Pandis, S. N., Facchini, M. C., Hansson, H.-C., Wiedensohler, A., and O'Dowd, C. D.: Introduction: European Integrated Project on Aerosol Cloud Climate and Air Quality interactions (EUCAARI) - integrating aerosol research from nano to global scales, Atmos. Chem. Phys., 9, 2825-2841, doi:10.5194/acp-9-2825-2009, 2009.

La Rosa, L. B., Buckley, T. J., and Wallace, L. A.: Real-time indoor and outdoor measurements of black carbon in an occupied house: an examination of sources, J. Air Waste Manage., 52(1), 174185, 2002.

Lack, D. A., Cappa, C. D., Covert, D. S., Baynard, T., Massoli, P., Sierau, B., Bates, T. S., Quinn, P. K., Lovejoy, E. R., and Ravishankara, A. R.: Bias in filter-based aerosol light absorption measurements due to organic aerosol loading: Evidence from ambient measurements, Aerosol Sci. Tech., 42, 1033-1041, doi:10.1080/02786820802389277, 2008.

Lack, D. A., Cappa, C. D., Cross, E. S., Massoli, P., Ahern, A. T., Davidovits, P., and Onasch, T. B.: Absorption Enhancement of Coated Absorbing Aerosols: Validation of the Photo-Acoustic Technique for Measuring the Enhancement, Aerosol Sci. Tech., 43, 1006-1012, doi:10.1080/02786820903117932, 2009.

Lindberg, J. D., Douglass, R. E., and Garvey, D. M.: Atmospheric particulate absorption and black carbon measurement, Appl. Optics, 38, 2369-2376, 1999.

Liousse, C., Cachier, H., and Jennings, S. G.: Optical and thermal measurements of black carbon aerosol content in different environments: variation of the specific attenuation cross-section sigma $(\sigma)$, Atmos. Environ., 27, 1203-1211, 1993.

Massoli, P., Baynard, T., Lack, D. A., Brock, C. A., Murphy, D. M., and Lovejoy, E. R.: Uncertainty in Light Scattering Measurements by TSI Nephelometer: Results from Laboratory Studies and Implications for Ambient Measurements, Aerosol Sci. Technol., 43, 1064-1074, doi:10.1080/02786820903156542, 2009.

Moteki, N., Kondo, Y., Nakayama, T., Kita, K., Sahu, L. K., Ishigai, T., Kinase, T., and Matsumi, Y.: Radiative transfer modeling of filter-based measurements of light absorption by particles: Importance of particle size dependent penetration depth, J. Aerosol Sci., 41, 401-412, 2010. 
Müller, T., Wiedensohler, A., Nowak, A., Laborde, M., Covert, D. S., Sheridan, P. J., Marinoni, A., Imre, K., Henzing, B., Roger, J. C., Martins dos Santos, S., Wilhelm, R., Wang, Y. Q., and de Leeuw, G.: Angular Illumination and Truncation of three Different Integrating Nephelometers: Implications for Empirical, Size-Based Corrections, Aerosol Sci. Tech., 43(43), 581-586, doi:10.1080/02786820902798484, 2009.

Nakayama, T., Kondo, Y., Moteki, N., Sahu, L. K., Kinase, T., Kita, K., and Matsumi, Y.: Size-dependent correction factors for absorption measurements using filter-based photometers: PSAP and COSMOS, J. Aerosol Sci., 41, 333-343, 2010.

Ogren, J. A.: Comment on "Calibration and Intercomparison of Filter-Based Measurements of Visible Light Absorption by Aerosols", Aerosol Sci. Tech., 44(8), 589-591, doi:10.1080/02786826.2010.482111, 2010.

Park, K., Chow, J. C., Watson, J. G., Trimble, D. L., Doraiswamy, P., Arnott, W. P., Stroud, K. R., Bowers, K., Bode, R., Petzold, A., and Hansen, A. D. A.: Comparison of Continuous and Filter-Based Carbon Measurements at the Fresno Supersite, J. Air Waste Manage., 56, 474-491, 2006.

Petzold, A., Kopp, C., and Niessner, R.: The dependence of the specific attenuation cross-section on black carbon mass fraction and particle size, Atmos. Environ., 31, 661-672, 1997.

Petzold, A. and Schönlinner, M.: Multi-angle absorption photometry - a new method for the measurement of aerosol light absorption and atmospheric black carbon, J. Aerosol Sci., 35, 421-441, 2004.

Petzold, A., Schloesser, H., Sheridan, P. J., Arnott, W., Ogren, J. A., and Virkkula, A.: Evaluation of multiangel absorption photometry for measuring aerosol light absorption, Aerosol Sci. Tech., 39, 40-51, 2005.

Raes, F., Bates, T., McGover, F., and van Liedekerke, M.: The 2nd Aerosol Characterization Experiment (ACE-2): general overview and main results, Tellus B, 52, 111-125, 2000.

Ramanathan, V., Crutzen, P. J., Lelieveld, J., Mitra, A. P., Althausen, D., Anderson, J., Andreae, M. O., Cantrell, W., Cass, G. R., Chung, C. E., Clarke, A. D., Coakley, J. A., Collins, W. D., Conant, W. C., Dulac, F., Heintzenberg, J., Heymsfield, A. J., Holben, B., Howell, S., Hudson, J., Jayaraman, A., Kiehl, J. T., Krishnamurti, T. N., Lubin, D., McFarquhar, G., Novakov, T., Ogren, J. A., Podgorny, I. A., Prather, K., Priestley, K., Prospero, J. M., Quinn, P. K., Rajeev, K., Rasch, P., Rupert, S., Sadourny, R., Satheesh, S. K., Shaw, G. E., Sheridan, P., and Valero, F. P. J.: Indian Ocean Experiment: An integrated analysis of the climate forcing and effects of the great Indo-Asian haze, J. Geophys. Res., 106(D22), 28371-28398, 2001.

Reid, J. S., Hobbs, P. V., Liousse, C., Martins, J. V., Weiss, R. E., and Eck, T. F.: Comparisons of techniques for measuring shortwave absorption and black carbon content of aerosols from biomass burning in Brazil, J. Geophys. Res., 103(D24), 3203132040, 1998.

Robles-Gonzalez, C., de Leeuw, G., Decae, R., KusmierczykMichulec, J., and Stammes, P.: Aerosol properties over the Indian Ocean Experiment (INDOEX) campaign area retrieved from ATSR-2, J. Geophys. Res., 111, D15205, doi:10.1029/2005JD006184, 2006.
Russell, P. B., Livingston, J. M., Hignett, P., Kinne, S., Wong, J., Chien, A., Bergstrom, R., Durkee, P., and Hobbs, P. V.: Aerosolinduced radiative flux changes off the United States mid-Atlantic coast: Comparison of values calculated from sunphotometer and in situ data with those measured by airborne pyranometer, J. Geophys. Res., 104(D2), 2289-2307, 1999.

Saathoff, H., Naumann, K. H., Schnaiter, M., Schock, W., Weingartner, E., Baltensperger, U., Kramer, L., Bozoki, Z., Pöschl, U., Niessner, R., and Schurath, U.: Carbon mass determinations during the AIDA soot aerosol campaign 1999, J. Aerosol Sci., 34(10), 1399-1420, 2003.

Schmid, O., Artaxo, P., Arnott, W. P., Chand, D., Gatti, L. V., Frank, G. P., Hoffer, A., Schnaiter, M., and Andreae, M. O.: Spectral light absorption by ambient aerosols influenced by biomass burning in the Amazon Basin. I: Comparison and field calibration of absorption measurement techniques, Atmos. Chem. Phys., 6, 3443-3462, doi:10.5194/acp-6-3443-2006, 2006.

Sheridan, P. J., Arnott, W. P., Ogren, J. A., Andrews, E., Atkinson, D. B., Covert, D. S., Moosmüller, H., Petzold, A., Schmid, B., Strawa, A. W., Varma, R., and Virkkula, A.: The Reno Aerosol Optics Study: An Evaluation of Aerosol Absorption Measurement Methods, Aerosol Sci. Tech., 39, 1-16, 2005.

Slowik, J. G., Cross, E. S., Han, J. H., Davidovits, P., Onasch, T. B., Jayne, J. T., Williams, L. R., Canagaratna, M. R., Worsnop, D. R., Chakrabarty, R. K., Moosmuller, H., Arnott, W. P., Schwarz, J. P., Gao, R. S., Fahey, D. W., Kok, G. L., and Petzold, A.: An Inter-Comparison of Instruments Measuring Black Carbon Content of Soot Particles, Aerosol Sci. Tech., 41(3), 295-314, doi:10.1080/02786820701197078, 2007.

Springston, S. R., Sedlacek, I., and Arthur, J.: Noise Characteristics of an Instrumental Particle Absorbance Technique, Aerosol Sci. Tech., 41(12), 1110-1116, 2007.

Subramanian, R., Roden, C. A., Boparai, P., and Bond, T. C.: Yellow beads and missing particles: Trouble ahead for filterbased absorption measurements, Aerosol Sci. Tech., 41, 630 637, doi:10.1080/02786820701344589, 2007.

Veihelmann, B., Levelt, P. F., Stammes, P., and Veefkind, J. P.: Simulation study of the aerosol information content in OMI spectral reflectance measurements, Atmos. Chem. Phys., 7, 3115-3127, doi:10.5194/acp-7-3115-2007, 2007.

Virkkula, A.: Correction of the Calibration of the 3-wavelength Particle Soot Absorption Photometer ( $3 \lambda$ PSAP), Aerosol Sci. Tech., 44, 706-712, doi:10.1080/02786826.2010.482110, 2010.

Virkkula, A., Ahlquist, N. C., Covert, D. S., Arnott, W. P., Sheridan, P. J., Quinn, P. K., and Coffmann, D. J.: Modification, calibration and a field test of an instrument for measuring light absorption by particles, Aerosol Sci. Tech., 39, 68-83, 2005.

Virkkula, A., Mäkelä, T., Yli-Tuomi, T., Hirsikko, A., Koponen, I. K., Hämeri, K., and Hillamo, R.: A simple procedure for correcting loading effects of aethalometer data, J. Air Waste Manage., 57, 1214-1222, doi:10.3155/1047-3289.57.10.1214, 2007.

Weingartner, E., Saathoff, H., Schnaiter, M., Streit, N., Bitnar, B., and Baltensperger, U.: Absorption of light by soot particles: Determination of the absorption by means of aethalometers, J. Aerosol Sci., 34, 1445-1463, 2003. 